\title{
A Human Lunar Surface Base and Infrastructure Solution
}

\author{
David K. Bodkin ${ }^{1}$, Paul Escalera ${ }^{2}$, and Kenneth J. Bocam ${ }^{3}$ \\ Orbital Sciences Corporation, Dulles, VA, 20166
}

\begin{abstract}
Orbital's Lunar Surface Infrastructure is comprised of five areas: Human Transport System, Cargo Transport System, Lunar Exploration Surface Infrastructure, Lunar InSpace Support Systems, and Lunar Precursor and Science System. This paper focuses on the Cargo Transport System and the Lunar Exploration Surface Infrastructure and discusses some of the critical challenges faced, alternatives considered, and Orbital's solution for these challenges. In addition to presenting a Lunar Surface Exploration architecture that fits within program constraints and highlighting the architecture defining trade studies, e.g. habitat geometry, habitat radiation shielding, lunar surface power, and cargo delivery system, a launch manifest and strategy for lunar base expansion are also discussed.
\end{abstract}

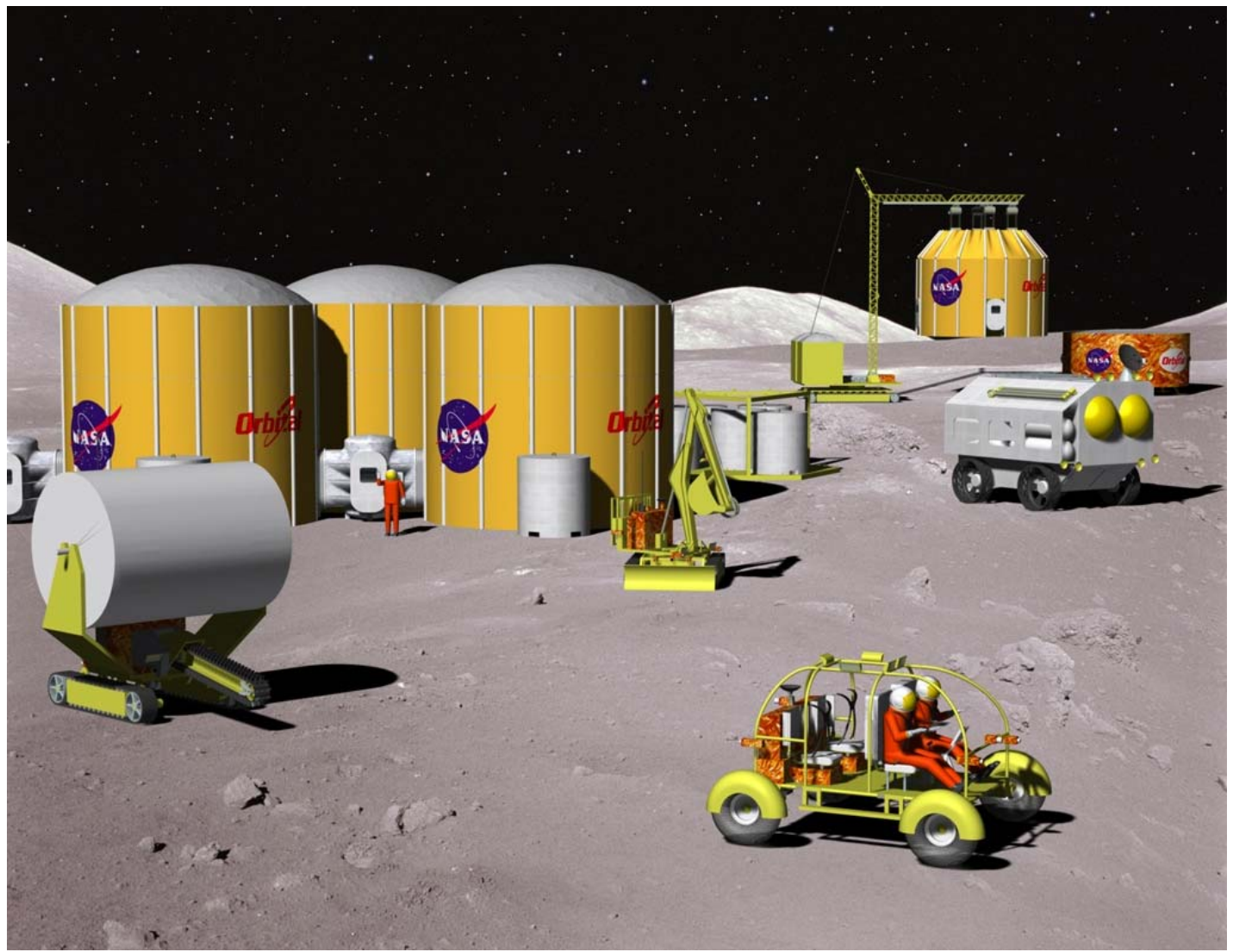

\footnotetext{
${ }^{1}$ Principal Engineer, Advanced Programs Group - Advanced Flight Systems, 21839 Atlantic Blvd., Member.

${ }^{2}$ Senior Engineer, Advanced Programs Group - Advanced Flight Systems, 21839 Atlantic Blvd., Member.

${ }^{3}$ Senior Principal Engineer, Advanced Programs Group - Advanced Flight Systems, 21839 Atlantic Blvd., Senior Member. 


\section{Introduction}

$\mathrm{R}$ ecent events within the aerospace community, such as the President's Vision for Space Exploration (VSE), the Exploration Systems Architecture Study (ESAS), and the Crew Exploration Vehicle (CEV) program, have generated much discussion on the space transportation segment of the lunar exploration mission. While transportation is a critical aspect of exploration, the discussion has not yet focused on the lunar surface base and infrastructure required to establish a sustained human presence on the moon. During the Concept Exploration and Refinement (CE\&R) Study sponsored by NASA, Orbital developed integrated solutions for transportation to the lunar surface and lunar surface infrastructure architectures that satisfied the program requirements and constraints.

\section{Program Assumptions and Driving Requirements}

Orbital Sciences Corporation’s Advanced Programs Group (APG) developed a lunar exploration architecture under contract to the National Aeronautics and Space Administration (NASA) during the Concept Exploration and Refinement (CE\&R) program in order to advise NASA on feasible requirements, missions, and the future direction of U.S space exploration. The principal objective of the CE\&R Study was to support NASA in its planning for the implementation of the Vision for Space Exploration by developing an initial concept for lunar exploration and a CEV development plan. The architecture described in this paper was developed in a trade space, which included technical factors, schedule constraints, and budgetary constraints. Throughout the study, a Technology Readiness Level (TRL) was used to assess the required technologies. The TRL is a scale used to reflect the maturity of a technology and how much is known about the technology's potential impacts. The scale goes from 1 to 9 with a 1 defined as "basic principles observed" and a 9 defined as "System flight proven through mission operations.” Architectural development risk was minimized by mandating that no technology with a TRL below 6 (6 is defined as "System/subsystem model or prototype demonstration in relevant environment”) would be considered for immediate implementation. Technologies of interest with TRLs of less than 6 required a development plan and corresponding budget to sufficiently mature the technology. The recommended development and acquisition plan is shown

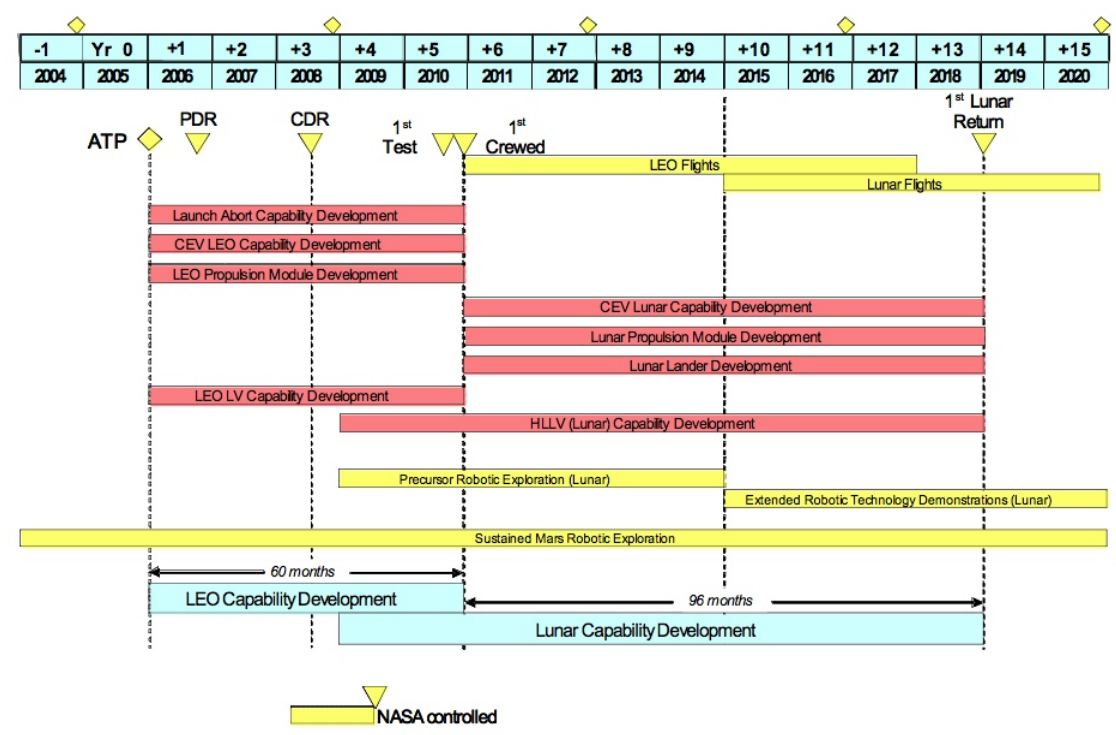

Figure 1. Recommended Development and Acquisition Plan in Fig. 1.

The development and acquisition approach was predicated on attaining two key objectives, crewed flight by 2010 and crewed lunar flight by 2020, while not exceeding the projected NASA budget profile. The development plan provides crewed CEV flights to Low Earth Orbit (LEO) in late 2010 and the first crewed lunar mission in early 2019. This development plan stays within NASA's proposed budget and nearly meets the yearly budget constraints. The primary reason for the near-term budget overruns was NASA's additional requirement for ISS support until 2011. This required the development of two additional architecture elements: a human-rated LEO launch vehicle and a LEO propulsion module.

Research and analysis showed that pre-deploying assets and verifying operational capability prior to the first sustained duration crewed mission to the surface of the moon increased mission duration and crew safety. The predeployed resources are the Maintenance Habitat Module with airlock, primary power supply (nuclear), backup power supply (solar/fuel cells), emergency power supply (battery), consumables for 120 crew days, redundant Human Lunar Lander (HLL) in orbit, crew transport rover, crawler crane surface transporter, and utility rover. The 
surface infrastructure assets need to be launched in 2017 to commence construction and integration to support a 2019 human landing. Figure 2 shows the proposed launch manifest associated with this approach.

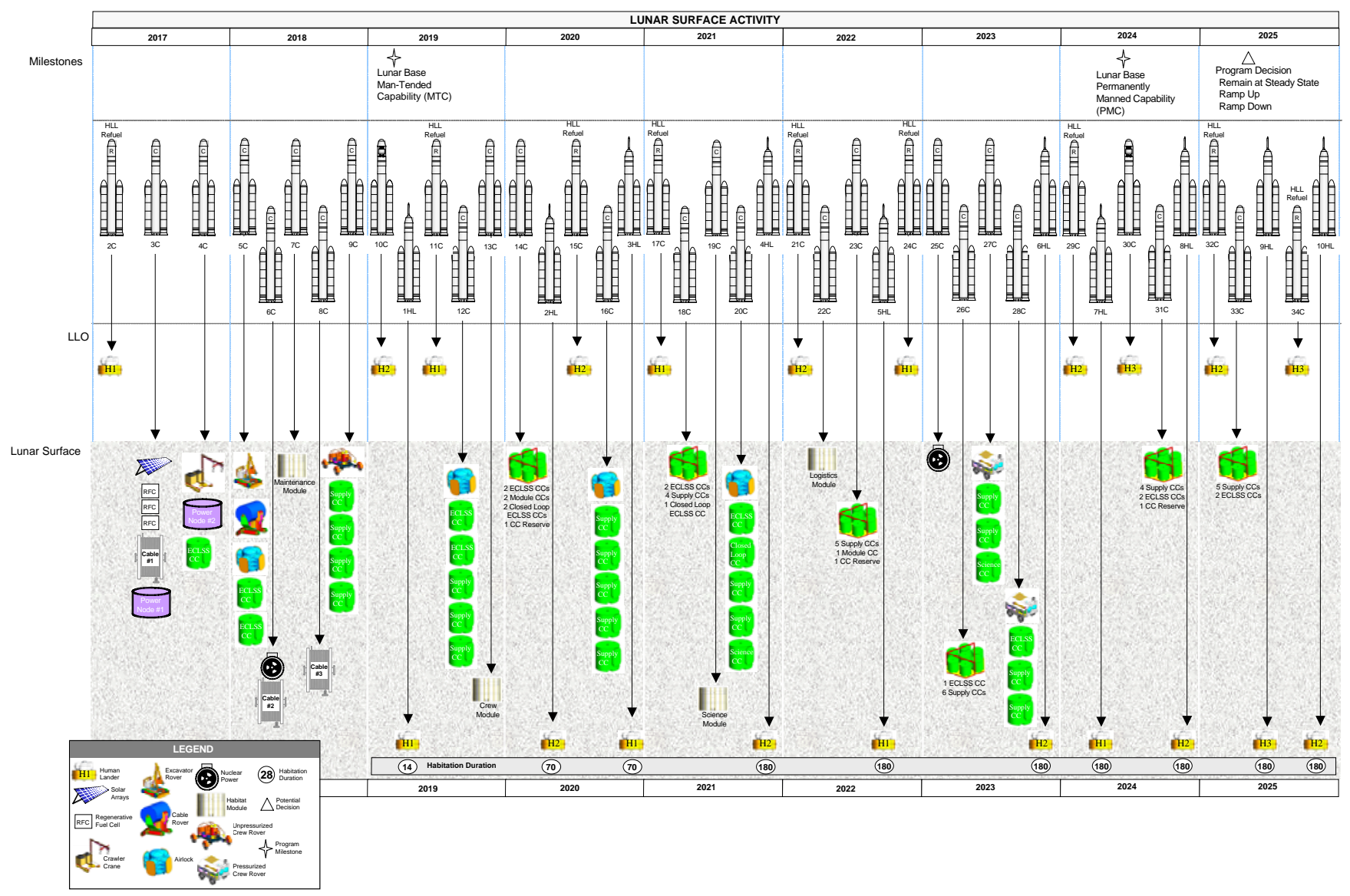

Figure 2. Proposed Launch Manifest

\section{Transportation System}

Establishing an operational lunar base begins with the transportation segment. While this paper focuses on the lunar surface base and infrastructure, it is critical to understand the interrelationships of the multiple systems within a System of Systems architecture. Specifically, it is imperative to understand the constraints and capabilities of the transportation system that delivers the infrastructure elements to the lunar surface and how it influences the Lunar Surface Infrastructure's (LSI's) development. Orbital's system breakdown structure for the entire exploration architecture is shown in Fig. 3.

The transportation capability in Orbital's exploration architecture is

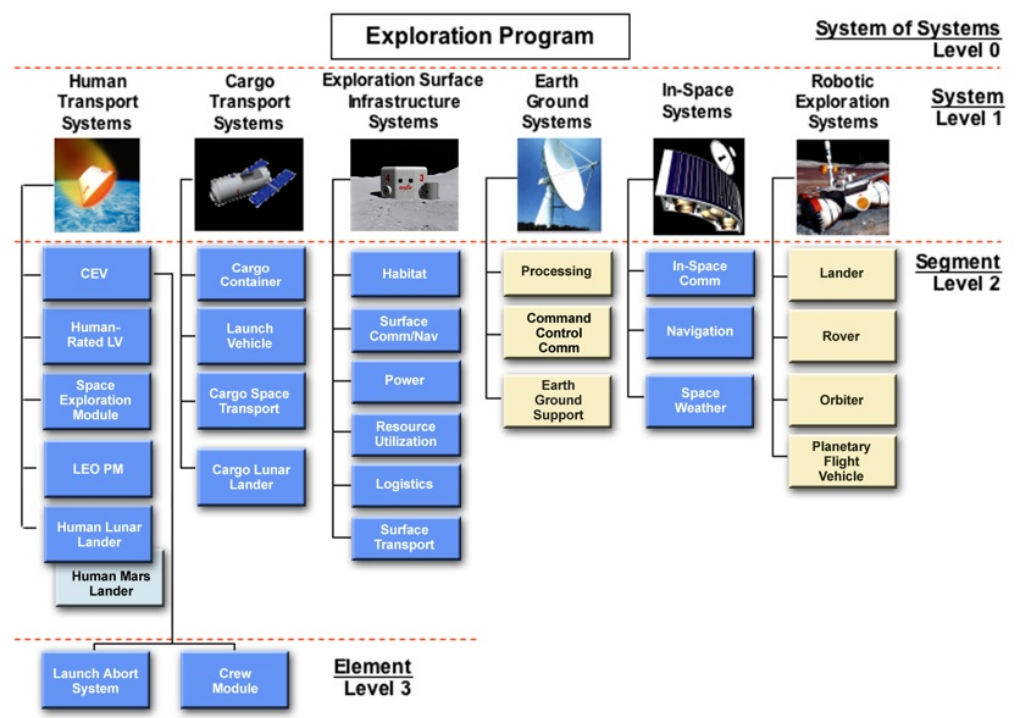

Figure 3. Exploration Program System Breakdown Structure. 
comprised of two discrete systems, the Human Transport System and the Cargo Transport System. The human and cargo transportation systems were developed concurrently with an emphasis on commonality. The Human Transport System (HTS) consists of all segments required for transporting a crew from the Earth's surface to the lunar surface. The major HTS elements include the Crew Exploration Vehicle (CEV), a Heavy Lift Launch Vehicle (HLLV), a Human Lunar Lander (HLL), and a Space Exploration Module (SEM) and can be seen in Fig. 4. ${ }^{1}$ These systems are used to execute a Lunar Orbit Rendezvous (LOR) style mission consisting of two HLLV launches. The first HLLV delivers the lander to lunar orbit and the second HLLV delivers the CEV to lunar orbit. The CEV is the vehicle that supports the crew and transports them from the Earth's surface to the destination vicinity. The HLLV, which is a shuttle derived human rated launch vehicle, launches the CEV and SEM. The SEM provides additional propulsion and crew consumables for the transfer from Earth orbit to lunar orbit. The HLL docks with the CEV in lunar orbit and transports the crew from lunar orbit to the lunar surface. The CEV and SEM provide the crew life support and propulsion during transportation back from the moon, ultimately only using the CEV for Earth reentry and recovery.

The Cargo Transport System (CTS) was developed to transport cargo from the Earth's surface to the Moon. The major CTS elements include a Heavy Lift Launch Vehicle (HLLV), a Cargo Lunar Lander (CLL), and a Space Exploration Module (SEM). All of these systems are cargo versions of the HTS elements. The Cargo SEM is a reduced functionality version of the human SEM concept, optimized for maximum payload delivery to lunar orbit. This variant of the SEM provides only oneway propulsion to lunar orbit and thus can deliver 38,828 $\mathrm{kg}(85,600 \mathrm{lbm})$ of payload to lunar orbit on a single mission. A cargo delivery mission to the Moon requires a SEM to deliver a lander to lunar orbit and a lander to deliver the cargo to the lunar surface. Most cargo elements will be launched on the HLLV; however, smaller cargo payloads may be launched on smaller launch systems as budgetary, operational or other constraints warrant. The Cargo Lunar Lander (CLL) base, containing propulsion avionics and power, was common with the HLL. ${ }^{2}$ The configuration was optimized for cargo missions by having all crew related systems removed including the airlock, crew compartment and Environmental Control and Life Support System (ECLSS). The cargo platform allowed for payloads $787 \mathrm{~cm}$ (310 in.) in diameter, volume of $285 \mathrm{~m}^{3}\left(10,063 \mathrm{ft}^{3}\right)$, and 26,978 $\mathrm{kg}(59,477 \mathrm{lbm})$ to the lunar surface. The CLL's purpose is to deliver all cargo to the lunar surface. This includes rovers, crawler cranes, habitat modules, power stations, and Cargo Containers (CC).

The CC is used as a common element throughout the architecture. It was sized to efficiently use the surface area of the CLL deck. The height of the CC was determined by analyzing data of $95^{\text {th }}$ percentile suited American Male. The resulting dimensions of the CC are $213 \mathrm{~cm}$ (84 in.) in diameter and $229 \mathrm{~cm}(90 \mathrm{in}$.) in height. The primary purpose of the $\mathrm{CC}$ is to transport smaller items, e.g. spare parts, science experiments, crew gear, and consumables. The CC's are pressurized and can attach either directly to a habitat module or to an airlock. By permitting direct access to the contents of the CC in this manner, the crew is not required to perform an EVA to load/unload cargo into/out of the habitat and therefore save valuable consumables. Either the Backhoe Utility Rover or the Crawler Crane (see Fig. 15 and 17b) transports the CC's. The interface for transport is either through a ring on the top of the CC or via the forklift cutouts located at the bottom of the pressure vessel. 


\section{Lunar Base Architecture}

To support long duration human exploration of the lunar surface specific functionality is required. Early in the CE\&R Study the following functionality was identified as required for lunar surface operations: habitation, power, life support, and mobility. Orbital's lunar base architecture fulfils these needs while carefully balancing requirements, crew safety, system weight, affordability, and technology readiness. The following sections will discuss some of the design details and assumptions for each of these elements, and the trades and analyses conducted to arrive at the final solution. The elements that comprise Orbital's lunar base architecture are depicted in Table 1.

Table 1. Lunar Surface Element Summary

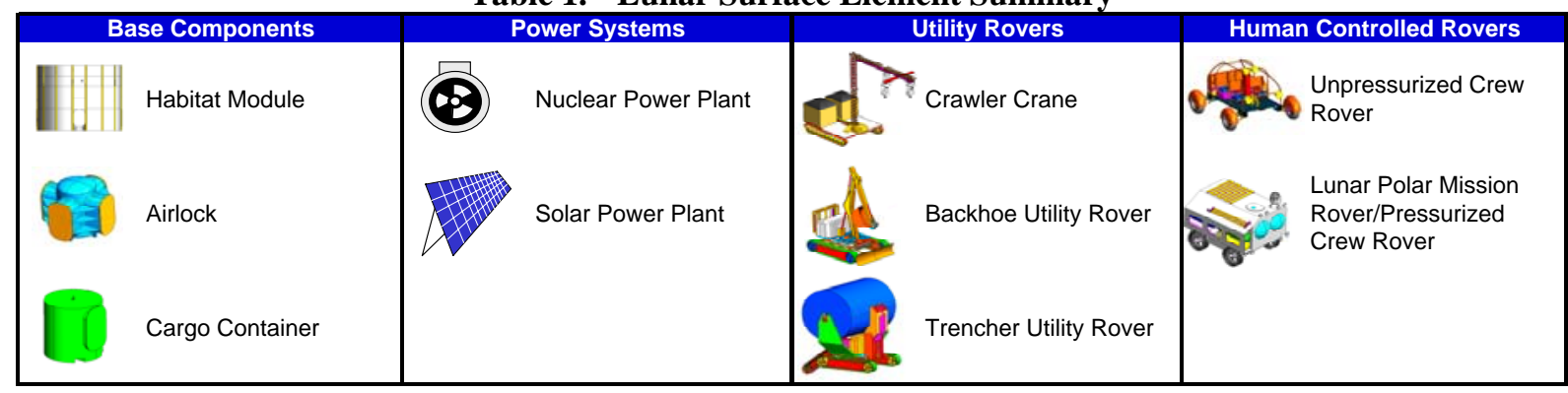

\section{A. Lunar Habitat}

The concept for the Lunar Habitat began with a few basic requirements. First and foremost, the habitat needs to be transported to the lunar surface via the CLL. This constrained the design geometrically, but also weight given the payload capability of the CLL. The geometry constraints are due to the CLL cargo area and the launch vehicle shroud dynamic envelope, which are shown in Fig. 5. The second constraint was a self-imposed requirement of phasing in functionality of the habitat. Since the habitat volume is limited by the HLLV shroud volume and payload capability, it was apparent that all the necessary functionality could not fly in a single habitat. The result was that the habitat elements needed to be modular to permit a phased in approach in fielding functionality.

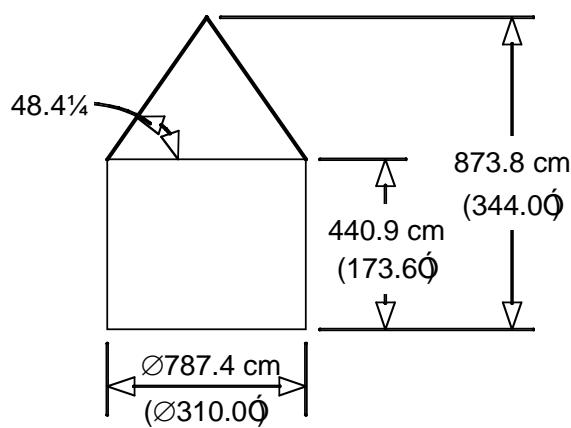

Figure 5. Habitat Module Geometry

A trade study was performed to evaluate habitat module geometries. Seven different configurations were selected for the trade study. Three vertical cylinders, a sphere, two toruses, and one horizontal cylinder were examined. The various habitat module geometries can be seen in Fig. 6.

The habitable volume and weight estimates of the geometries were compared to determine the most optimal configuration.

This optimized the habitat module weight, which is a major driver of the system

\begin{tabular}{|c|c|c|c|c|c|c|c|c|c|c|c|c|c|c|c|c|c|c|}
\hline \multirow[t]{2}{*}{ Case } & \multirow[t]{2}{*}{ Shape } & \multicolumn{2}{|c|}{$\begin{array}{c}\text { Total } \\
\text { Volume }\end{array}$} & \multicolumn{2}{|c|}{$\begin{array}{l}\text { Livable } \\
\text { Volume }\end{array}$} & \multirow[t]{2}{*}{ Group } & \multicolumn{2}{|c|}{ Shell Thickness } & \multicolumn{2}{|c|}{ Shell Mass } & \multicolumn{2}{|c|}{ Floor Area } & \multicolumn{2}{|c|}{$\begin{array}{l}\text { Floor and Ceiling } \\
\text { Mass }\end{array}$} & \multicolumn{2}{|c|}{ Combined Mass } & \multicolumn{2}{|c|}{ Mass/Volume Ratio } \\
\hline & & $\mathrm{m}^{3}$ & $\mathrm{ft}^{3}$ & $\mathrm{~m}^{3}$ & $\mathrm{ft}^{3}$ & & $\mathrm{~cm}$ & in & $\mathrm{kg}$ & $\mathrm{Ibm}$ & $\mathrm{m}^{2}$ & $\mathrm{ft}^{2}$ & $\mathrm{~kg}$ & & $\mathrm{~kg}$ & $\mathrm{lbm}$ & $\mathrm{kg} / \mathrm{m}^{3}$ & $1 \mathrm{bm} / \mathrm{ft}^{3}$ \\
\hline $1 \mathrm{~A}$ & Baseline & 132.1 & 4.665 & 92.7 & 3,272 & All & 0.919 & 0.362 & 3300 & 7,275 & 37 & 394 & 182 & 402 & 3482 & 7,677 & $\frac{\pi y / 11}{26.4}$ & 1.646 \\
\hline $1 \mathrm{~B}$ & $\begin{array}{l}\text { Bseline, Varied } \\
\text { Element Thickness }\end{array}$ & 132.1 & 4,665 & 92.7 & 3,272 & $\begin{array}{l}\text { Tunnel } \\
\text { Hatch Area } \\
\text { Cylinder } \\
\text { End Dome }\end{array}$ & $\begin{array}{l}0.841 \\
0.978 \\
0.267 \\
0.612\end{array}$ & $\begin{array}{l}0.331 \\
0.385 \\
0.105 \\
0.241\end{array}$ & 1954 & 4,308 & 37 & 394 & 182 & 402 & 2,136 & 4,710 & 16.2 & 1.010 \\
\hline $2 \mathrm{~A}$ & Expanded Baseline & $\mid 161.9$ & 5,717 & 92.7 & 3,272 & All & 0.848 & 0.334 & 3429 & 7,560 & 37 & 394 & 182 & 402 & 3612 & 7,962 & 22.3 & 1.393 \\
\hline $2 \mathrm{~B}$ & $\begin{array}{l}\text { Expanded Baseline, } \\
\text { Varied Element } \\
\text { Thickness }\end{array}$ & \begin{tabular}{|l|}
161.9 \\
\end{tabular} & 5,717 & 92.7 & 3,272 & $\begin{array}{l}\text { Tunnel } \\
\text { Hatch Area } \\
\text { Cylinder } \\
\text { End Dome }\end{array}$ & $\begin{array}{l}0.765 \\
0.932 \\
0.254 \\
0.584\end{array}$ & $\begin{array}{l}0.301 \\
0.367 \\
0.100 \\
0.230\end{array}$ & 1973 & 4,349 & 37 & 394 & 182 & 402 & 2,155 & 4,751 & 13.3 & 0.831 \\
\hline $3 \mathrm{~A}$ & Sphere & 142.5 & 5,031 & 79.8 & 2,817 & All & 0.574 & 0.226 & 2059 & 4,540 & 28 & 300 & 137 & 302 & 2196 & 4,842 & 15.4 & 0.962 \\
\hline зв & $\begin{array}{l}\text { Sphere, Varied } \\
\text { Element Thickness }\end{array}$ & 142.5 & 5,031 & 79.8 & 2,817 & $\begin{array}{l}\text { Tunnel } \\
\text { Hatch Area } \\
\text { Sphere }\end{array}$ & $\begin{array}{l}0.650 \\
0.495 \\
0.152\end{array}$ & $\begin{array}{l}0.256 \\
0.195 \\
0.060\end{array}$ & 803 & 1,770 & 28 & 300 & 137 & 302 & 940 & 2,072 & 6.6 & 0.412 \\
\hline $4 \mathrm{~A}$ & Torus & 90.13 & 3,183 & 81.1 & 2,864 & All & 0.432 & 0.170 & 1346 & 2,968 & 20 & 214 & 88 & 194 & 1434 & 3,162 & 15.9 & 0.993 \\
\hline $4 \mathrm{~B}$ & \begin{tabular}{|l} 
Tours, Varied \\
Element Thickness
\end{tabular} & 90.13 & 3,183 & 81.1 & 2,864 & $\begin{array}{l}\text { Tunnel } \\
\text { Hatch Area } \\
\text { Torus }\end{array}$ & $\begin{array}{l}0.493 \\
0.419 \\
0.152\end{array}$ & $\begin{array}{l}0.194 \\
0.165 \\
0.060\end{array}$ & 637 & 1,404 & 20 & 214 & 88 & 194 & 725 & 1,598 & 8.0 & 0.502 \\
\hline $5 \mathrm{~A}$ & Toroid & 159.5 & 5,631 & 91.2 & 3,221 & & 0.1526 & 0.000 & 3683 & 8,120 & 36 & 387 & 179 & 395 & 1174 & 2,589 & 7.4 & 1.512 \\
\hline $5 B$ & $\begin{array}{l}\text { Toroid, Varied } \\
\text { Element Thickness }\end{array}$ & 159.5 & 5,631 & 91.2 & 3,221 & $\begin{array}{l}\text { Tunnel } \\
\text { Hatch Area } \\
\text { Outer Wall } \\
\text { Inner Wall } \\
\text { End Dome }\end{array}$ & $\begin{array}{l}0.782 \\
0.965 \\
0.998 \\
0.152 \\
0.152 \\
\end{array}$ & $\begin{array}{l}0.308 \\
0.380 \\
0.078 \\
0.060 \\
0.060 \\
\end{array}$ & 995 & 2,194 & 36 & 387 & 179 & 395 & 1,174 & 2,589 & 7.4 & 0.460 \\
\hline $6 \mathrm{~A}$ & 0.707 & \begin{tabular}{|l|l}
158.4 \\
\end{tabular} & 5,595 & 91.2 & 3,219 & & 0.605 & 0.238 & 2266 & 4,9966 & 33 & 355 & 166 & 367 & 2433 & 5,363 & 15.4 & 0.959 \\
\hline $6 \mathrm{~B}$ & $\begin{array}{l}0.707, \text { Varied } \\
\text { Element Thickness }\end{array}$ & 158.4 & 5,595 & 91.2 & 3,219 & $\begin{array}{l}\text { Tunnel } \\
\text { Hatch Area } \\
\text { Cylinder } \\
\text { End Dome }\end{array}$ & $\begin{array}{l}0.546 \\
0.630 \\
0.152 \\
0.152\end{array}$ & $\begin{array}{l}0.215 \\
0.248 \\
0.060 \\
0.060\end{array}$ & 755 & 1,664 & 33 & 355 & 166 & 367 & 921 & 2,031 & 5.8 & 0.363 \\
\hline $7 \mathrm{~A}$ & Hotdog & \begin{tabular}{|l|l}
124.8 \\
\end{tabular} & 4,408 & 79.5 & 2,809 & & 0.1526 & 0.219 & 1857 & \begin{tabular}{|l|}
4,095 \\
\end{tabular} & 22 & 241 & 113 & 249 & 1970 & 4,344 & 15.8 & 0.986 \\
\hline $7 \mathrm{~B}$ & $\begin{array}{l}\text { Hotdog, Varied } \\
\text { Element Thickness }\end{array}$ & 125 & 4,408 & 79.5 & 2,809 & $\begin{array}{l}\text { Tunnel } \\
\text { Hatch Area } \\
\text { Cylinder } \\
\text { End Dome }\end{array}$ & $\begin{array}{l}0.483 \\
0.577 \\
0.229 \\
0.152\end{array}$ & $\begin{array}{l}0.2190 \\
0.227 \\
0.090 \\
0.060\end{array}$ & 567 & 1,251 & 22 & 241 & 113 & 249 & 680 & 1,500 & 5.5 & 0.340 \\
\hline
\end{tabular}


architecture cost. Radiation protection was not considered in this trade due to the density of metals and the amount of protection that they offer. At the habitat thicknesses being specified in this trade space, protection from radiation is negligible. The weight estimates were based on Finite Element Models (FEMs). Two loading conditions were considered, acceleration loads on ascent and internal pressurization of the habitat module. The material used on all geometries was $\mathrm{Al}-\mathrm{Li} 8091$ with a minimum gauge thickness of $0.152 \mathrm{~cm}(0.060 \mathrm{in}$.) due to manufacturing limitations. A summary of the results can be seen in Table 2. Two cases were run for each geometry. The "A" cases

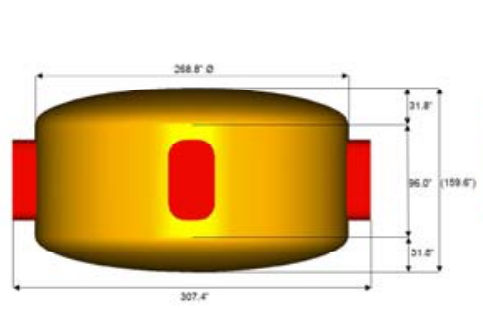

a)

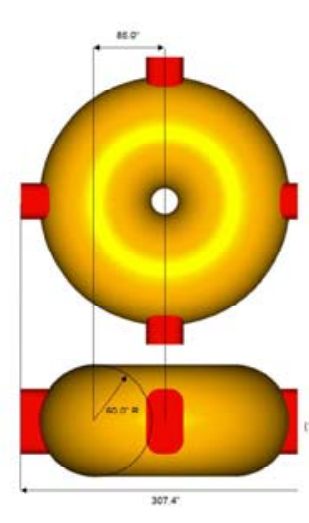

d)

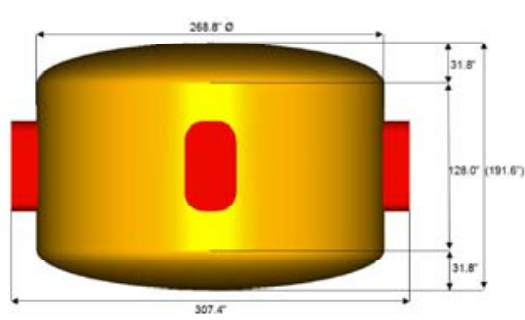

b)

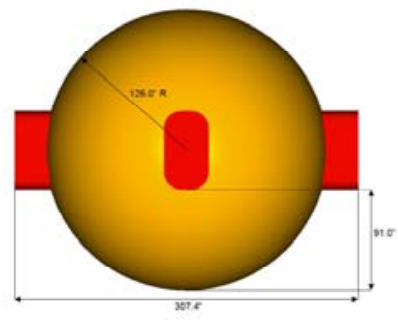

c)

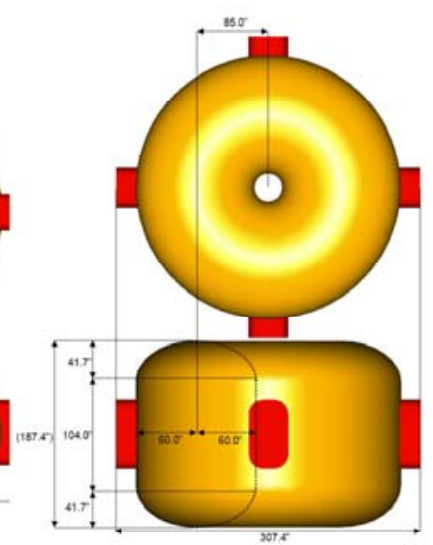

e)

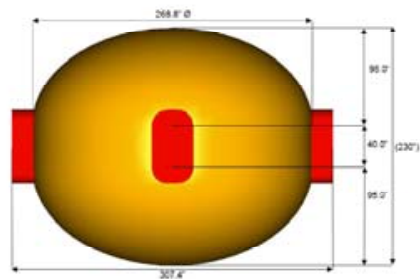

f)

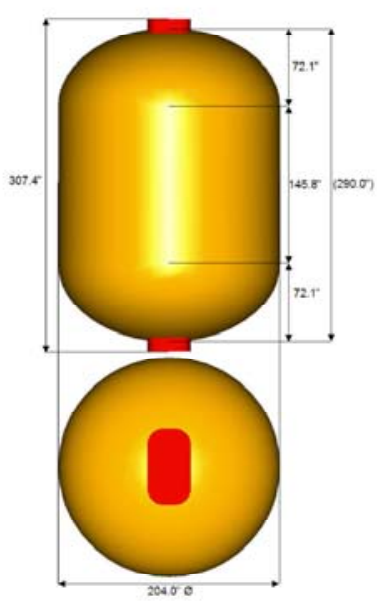

g)

Figure 6. Geometries Considered for the Habitat Module. a) Baseline b) Expanded Baseline c) Sphere d) Torus e) Toroid f) 0.707 g) Hotdog.

all had a uniform thickness that was derived from the maximum stress location. The "B" cases optimized thickness for different areas, thus allowing areas of low stress to have a smaller wall thickness. From this analysis, the conclusion was drawn that optimizing material thickness throughout the geometry has significant weight savings (see "B" cases in Table 2). It is also noted that although Case 1B has the highest livable volume, it has the highest mass per volume ratio of the varied thickness cases (a lower mass per volume ratio is more desirable). Also worth mentioning is Case 7B (a.k.a. the Hotdog). This geometry had the lowest mass per volume ratio of all the varied element thickness cases; however, the hotdog offered the lowest livable and lowest overall volumes. This was largely due to the Hotdog inefficiently using the cargo floor of the CLL and being limited by the constraints of the launch vehicle shroud. The trade study resulted in the recommendation of Case 6B (0.707, Varied Element Thickness). This geometry came in a close second in the Mass/Volume ratio to the Hotdog geometry, but surpassed the Hotdog in Floor Area and Total and Livable Volumes. The total volume of this geometry was calculated to be $158 \mathrm{~m}^{3}\left(5,595 \mathrm{ft}^{3}\right)$ with livable volume of $92.1 \mathrm{~m}^{3}\left(3,219 \mathrm{ft}^{3}\right)$.

Since the lunar base required a modular design to support the philosophy of phasing in habitat functionality, airlocks were required to perform as interface modules between the habitat modules. The goal of the design concept was to optimize the amount of commonality between units. To accomplish this, the airlock's design was based on the CC with some slight modifications. The airlock was designed to accommodate two crewmembers donning/doffing their spacesuits. Additionally, tunnels were added for integration of the airlocks and CC's with the habitat modules. 
One of the significant safety concerns of astronauts undertaking a sustained duration stay on the lunar surface is radiation, from Solar Particle Events (SPEs) and a bombardment of Galactic Cosmic Radiation. The crew will require protection that can mitigate this safety risk. Since the crew will be spending large amounts of time inside the habitat, it is logical that the habitats will require shielding from these radiation sources. To start the analysis, the environment of the February 1956 SPE was selected. ${ }^{3}$ This event was selected because it delivered more protons of $200 \mathrm{MeV}$ or greater compared to August 1972 and November 1960 SPEs. Research was performed examining materials to provide radiation shielding. From this study, polyethylene emerged as the baseline radiation shielding material. The strategy was to include polyethylene shielding in the habitat to protect the crew and provide a safe haven at Lunar Base Initial Operating Condition. An analysis was performed to determine the amount of polyethylene required to mitigate the February 1956 SPE and it was determined that $19.05 \mathrm{~cm}(7.5 \mathrm{in}$.) of polyethylene are required to protect the crew. This resulted in the addition of $6,804 \mathrm{~kg}(15,000 \mathrm{lbm})$ to the Habitat Modules and only covered the top of the habitat module. The additional mass resulting from the shielding made the concept a "non-starter" due to the ripple effect that would carry down through the Transportation Segment including CLL, SEM, and HLLV and would affect the payload delivered to the lunar surface and number of missions due to the additional mass.

Results of further research yielded the concept of using in-situ resources to provide radiation shielding, namely lunar soil or regolith. Analysis determined that using $50.8 \mathrm{~cm}$ (20 in.) of regolith as a radiation shield [assumes regolith average density of 1.5 $\left.\mathrm{g} / \mathrm{cm}^{3}\left(0.054 \mathrm{lb} / \mathrm{in}^{3}\right)\right]$ will mitigate the same February $1956 \mathrm{SPE}^{4}$ While this resulted in more installed mass, it was not added to the habitat module until it was deployed on the lunar surface and therefore did not impact the transportation system or mission manifest. The habitat module was designed with a retaining wall made of Kevlar/Vectran cloth placed around the

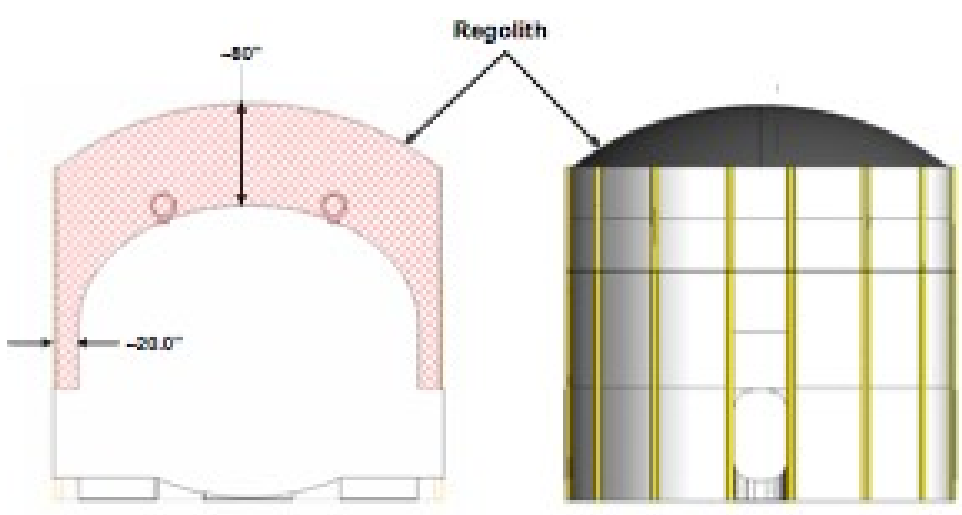

Figure 7. Habitat Module with Regolith Fence. Habitat crosssection depicting regolith thickness (l). External view of Habitat Module (r). perimeter of the module to ensure thickness uniformity. This feature of the habitat module provided safety for the crew at all incident angles as opposed to polyethylene where the crew was only safe if the radiation particle path was perpendicular to the lunar surface or close angles there to. A self-imposed requirement was levied on the habitat system to be able to protect the crew from a SPE of four times (4X) greater than the February 1956 event. A linear relationship between regolith thickness and radiation shielding was assumed and resulted in the habitat requiring 80 inches of regolith coverage. Figure 7 depicts the habitat module with the Kevlar/Vectran retaining wall and a cross section showing the depth of regolith coverage.

Table 3. Habitat Module Functionality.

\begin{tabular}{|c|l|l|}
\hline Habitat Module & Module Functionality & \multicolumn{1}{|c|}{ Module Systems } \\
\hline Crew Module & Supports up to 4 crew & $\begin{array}{l}\text { ECLSS Management } \\
\text { Power Management } \\
\text { Thermal Control } \\
\text { Galley } \\
\text { Communications } \\
\text { Hygiene } \\
\text { Dining/Wardroom } \\
\text { Laundry } \\
\text { Health }\end{array}$ \\
\hline Science Module & $\begin{array}{l}\text { Science } \\
\text { Exercise }\end{array}$ & $\begin{array}{l}\text { Power Management } \\
\text { Thermal Control } \\
\text { Communications }\end{array}$ \\
\hline Maintenance Module & $\begin{array}{l}\text { Dust Control/Removal } \\
\text { Maintenance } \\
\text { Storage } \\
\text { Hygiene }\end{array}$ & $\begin{array}{l}\text { Power Management } \\
\text { Thermal Control } \\
\text { Communications }\end{array}$ \\
\hline Logistics Module & $\begin{array}{l}\text { Storage } \\
\text { Maintenance }\end{array}$ & $\begin{array}{l}\text { Power Management } \\
\text { Thermal Control } \\
\text { Communications }\end{array}$ \\
\hline
\end{tabular}

Since a single habitation module that contains all the necessary functionality is not feasible given launch vehicle constraints, functionality is spread out over multiple modules. It is critical to understand the functions that each habitat module can support and when that functionality will be phased in. The functionality is designed into the module so it can support the crew and the tasks associated at that point in the development schedule. Four habitation modules were designated as the baseline lunar base: Crew Module (HCM), Science Module (HSM), Maintenance Module (HMM), and Logistics Module (HLM). The functions for each module are shown in Table 3. 
The Proposed Launch Manifest (see Fig. 2) depicts the order in which the Habitat Modules will be dispatched to the lunar surface. The first module to arrive on the lunar surface is the Maintenance Module. This module is equipped to perform the functions of dust control/removal, maintenance, storage, and hygiene. Lunar dust control/removal can be considered the HMM's most important contribution. Lunar dust is highly corrosive and toxic to humans and mitigation of this risk plays a crucial role in the system life cycle. ${ }^{5,} 6$ The dust mitigation strategy is a phased approach. Phase 1 is a "blow down" in the airlock where loose dust would be vented back to the lunar surface. The astronaut then enters into the HMM in a containment section where the astronaut attaches the spacesuit to a wall and enters into the module through the use of suit ports. This approach contains the lunar dust to the chamber and greatly reduces the dust entering into the habitat. The feasibility of this approach requires further studies and

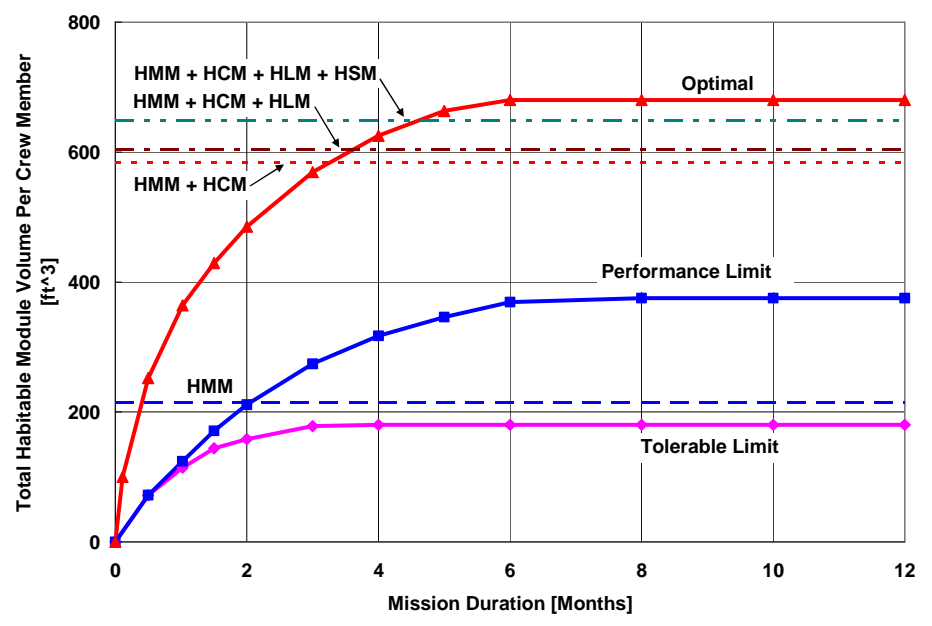

Figure 8. Habitable Volume Comparison of Lunar Base and NASA STD-3000. refinement.

The HMM provides enough habitable volume for the first extended duration stay of the campaign ( 14 days) for four crewmembers. As other modules are added, the habitable volume increases and can accommodate longer duration stays due to the increased volume and because of the increased functionality that each habitation module

\begin{tabular}{|c|c|c|}
\hline $\begin{array}{c}\text { Lunar Base Configurations } \\
\text { Considered }\end{array}$ & Characteristics & Assessment \\
\hline & $\begin{array}{l}\text { - Simple Layout, But Has A "Dead Zone"; Easy Buildup } \\
\text { - } 4 \text { Airlocks (Assumes Single Airlock Door Used for Habitat Ingress \& Egress) } \\
\text { - } 4 \text { Airlock Access Doors Unusable (Face "Dead Zone") } \\
\text { - Permits Up to } 8 \text { CC Habitat Dockings; Permits Up to } 3 \text { CC Airlock Dockings } \\
\text { - Failure of Single Airlock Limits Access From A Habitat Module To Only One } \\
\text { Other Habitat Module Via Available Airlock } \\
\text { - Failure of Single Habitat Module Limits Access to Other Modules }\end{array}$ & $\begin{array}{l}\text { - Inability to Provide Crew With Multiple } \\
\text { Escape Routes During an Airlock or } \\
\text { Habitat Failure Eliminates This } \\
\text { Configuration From Consideration }\end{array}$ \\
\hline & $\begin{array}{l}\text { - Simplest Layout, No "Dead Zone" } \\
\text { - } 4 \text { Airlocks (Assumes Single Airlock Door Used for Habitat Ingress \& Egress) } \\
\text { - Permits Up to } 9 \text { CC Habitat Dockings; Permits Up to } 8 \text { CC Airlock Dockings } \\
\text { - Failure of Single Airlock or Habitat Module Prevents Access To Other Habitat } \\
\text { Modules }\end{array}$ & $\begin{array}{l}\text { - Inability to Provide Crew With Multiple } \\
\text { Escape Routes During an Airlock or } \\
\text { Habitat Module Failure Eliminates This } \\
\text { Configuration From Consideration }\end{array}$ \\
\hline & $\begin{array}{l}\text { - No "Dead Zone": Complex Buildup } \\
\text { - } 5 \text { Airlocks (Assumes Single Airlock Door Used for Habitat Ingress \& Egress) } \\
\text { - Permits Up to } 6 \text { CC Habitat Dockings; Permits Up to } 5 \text { CC Airlock Dockings } \\
\text { - In Most Cases, Failure in Single Airlock Permits Access From A Habitat Module } \\
\text { to More Than One Habitat Module Via Other Available Airlock } \\
\text { - In Most Cases. Failure of Single Habitat Module Does Not Limit Access to Other } \\
\text { Habitat Modules to Only One Airlock (The Exception Being Module B) }\end{array}$ & $\begin{array}{l}\text { - In Most Cases, Access to Other Habitat } \\
\text { Modules is Not Restricted if an Airlock or } \\
\text { Habitat Module Failure Occurs } \\
\text { - Permits } 11 \text { CC Dockings }\end{array}$ \\
\hline & $\begin{array}{l}\text { - No "Dead Zone"; Complex Buildup } \\
\text { - } 4 \text { Airlocks (Assumes Single Airlock Door Used for Habitat Ingress \& Egress) } \\
\text { - Permits Up to } 5 \text { CC Habitat Dockings, Permits Up to } 5 \text { CC Airlock Dockings } \\
\text { - One Unusable CC Habitat Port } \\
\text { - In Most Cases. Failure in Single Airlock Permits Access to More Than One } \\
\text { Habitat Module Via Other Airlock (Exception Being Center Airlock) } \\
\text { - In All Cases, Failure of Single Habitat Module Does Not Limit Access to Other } \\
\text { Habitat Modules to Only One Airlock }\end{array}$ & $\begin{array}{l}\text { - Capability to Provide Unrestricted Access } \\
\text { to Other Habitat Modules In the Event of a } \\
\text { Habitat Module Failure is Beneficial }\end{array}$ \\
\hline Staggered & $\begin{array}{l}\text { - No "Dead Zone"; Complex Buildup } \\
\text { - } 4 \text { Airlocks (Assumes Single Airlock Door Used for Habitat Ingress \& Egress) } \\
\text { - Permits Up to } 6 \text { CC Habitat Dockings; Permits Up to } 5 \text { CC Airlock Dockings } \\
\text { - In Most Cases, Failure in Single Airlock Permits Access to More Than One } \\
\text { Habitat Module Via Other Airlock } \\
\text { - In All Cases, Failure in Single Habitat Module Does Not Restrict Access to Other } \\
\text { Habitat Modules }\end{array}$ & $\begin{array}{l}\text { - Has Characteristics of "Yellow" } \\
\text { Configurations Above } \\
\text { - Permits } 11 \text { CC Dockings } \\
\rightarrow \text { Preferred Configuration }\end{array}$ \\
\hline
\end{tabular}

Figure 9. Lunar Base Configurations Considered. 
adds. The habitable volume from NASA STD-3000 was used, since there is no accepted standard for habitable volume at partial gravity, which is applicable to zero $g$ and micro g environments. Further research and studies will need to be performed to examine habitable volume. It is recommended that this value should be approached as a habitable area since the crew will be restricted due to gravitational forces. Figure 8 shows the volume composition for the Lunar Base as a function of module quantity. Having the HMM deployed as the first module is sufficient for stays up to two months, assuming the "Performance Limit" is the lowest limit used.

A trade study was performed to examine the optimal layout given a four module lunar base. Ground rules were established for the evaluation of layouts: 1) All configurations considered will require four airlocks, 2) A habitat or airlock failure must permit access to other habitat modules, 3) Must maximize the number of CC interfaces, and 4) Maintenance access is not required through the regolith retaining walls (access to systems requiring maintenance is accessible from inside the pressure vessel). The five distinct configurations evaluated; Square, In-Line, Right Triangle, Star, and Staggered; are shown in Fig. 9. Significant characteristics are identified for each configuration and an assessment is given. Deploying the modules in a straight line was immediately ruled out due to the safety concern if the module's only exit/entrance was blocked. The Straight configuration also requires the crew to travel the furthest distance from one side of the base to the other which was considered a logistical constraint. The Square configuration was the most logical given the four different modules and the four vertices of a square. But after further consideration, the Staggered configuration became the configuration of choice. While both configurations permit the interface with airlocks and ECLS CCs, the Staggered uses one less airlock, which saves cargo room on a CLL flight and more efficiently uses the available area. The Square configuration had a "dead zone" in the middle that was unusable. While the Right Angle, Star, and Staggered configurations all permit a high number of airlocks and ECLS CCs interfaces, the Staggered configuration possesses the benefits of other two. Thus, the Staggered configuration was determined to be the configuration of choice and can be seen in Fig. 10. The numbers under each module name highlight the order in which they are fielded on the lunar surface.

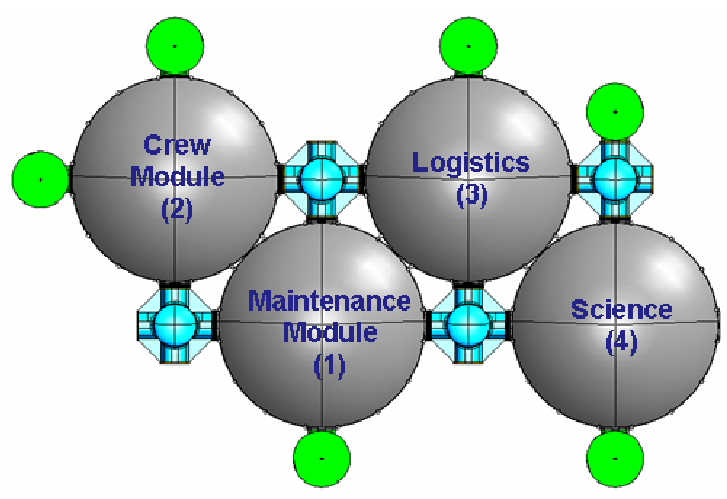

Figure 10. Staggered Configuration.

\section{B. Lunar Surface Power}

It was determined during the CE\&R study that power was critical in fielding a robust and sustainable Lunar Base Architecture since a power failure could risk loss of mission and also put the crew in jeopardy. For this reason, a Primary and Back-up Power System were included in the architecture. Basic requirements for the power systems are to provide power for both nominal and emergency operations and during the lunar night.

A power budget for sustained lunar base operations was determined taking into consideration nominal and emergency conditions and the lunar day-night cycle. The nighttime power scenario was found to be the driving case due to lighting requirements. Nominal lunar base power demand for each habitat module, airlock operation (including dust removal), and rover recharging was found to be approximately $200 \mathrm{kWe}$. A $20 \%$ factor was applied to each basic estimate to arrive at the margined value above. Also briefly considered was the use of habitat walls for the mounting of solar cells. This concept was disregarded in favor of more efficient sun pointing solar array concepts. Mounting the solar cells on the habitat walls also had a disadvantage in terms of collecting regolith dust from the process of implementing lunar regolith as radiation shielding for the habitat (ref. Section IV, Part A) and therefore degrading the performance. Lastly, the mass associated with storing the power collected from the solar cells (i.e. batteries) pushed the mass of the habitat beyond the capability of the launch vehicle.

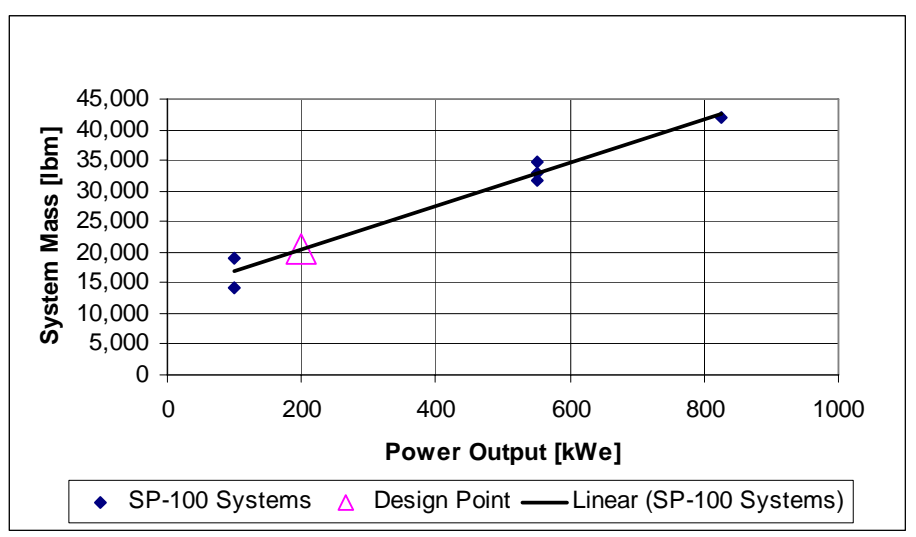

Figure 11. Nuclear Power System Mass v. Power Output. 
Taking these into consideration, the optimal solution was to decouple the power system from the habitat.

The primary power source is a buried $200 \mathrm{kWe}$ nuclear power plant that would be placed approximately one kilometer from any crewed activity to minimize crew radiation exposure. The goal of the CE\&R study was to develop an integrated Lunar Base and infrastructure solution and not to design individual systems. New technologies will undoubtedly add to the trade space in the future, but the SP-100 reactor was chosen largely for its available data. Research on nuclear power systems that used the SP-100 reactor yielded a linear relationship between power output and system mass. ${ }^{7,9,10}$ The result of this survey can be seen in Fig. 11. The System Mass includes a reactor assembly, activation shield, heat exchanger, power conversion, radiators, power processing and control, and structure. All systems assume a buried reactor and regolith shielding. Figure 11 includes data from both Brayton and Sterling engine concepts using both 4 and 5 engines. It was seen that reliability did not increase substantially if two standby engines were used. This resulted in the selection of a concept with four engines, three primary and one in standby mode. Between the Brayton and Sterling concepts, the Brayton design was selected because they can easily scale from 100kWe to Megawatt applications. This is appealing because of the extensibility it allows for adding future modules and vehicles to the Lunar Base. Another reason for selecting the Brayton design was due to the fact that they are good candidate systems for electric propulsion. ${ }^{11}$ This would permit capitalizing on an existing system at the time or be a forerunner for development of a new propulsion system through the use of commonality. Following the trend in Fig. 11, a system mass of 9,072 kg $(20,000 \mathrm{lbm})$ is estimated for sizing our 200kWe nuclear reactor. This system mass is within the CLL mass delivery constraint of approximately 15,876 kg (35,000 lbm). The reactor, at $100 \%$ capacity, is expected to last from eight to 10 years. The nuclear power plant provides power to surface assets via a series of redundant cables and power nodes.

The backup power system will play a supporting role to the primary source in the event of malfunction or failure, but it is also implemented as the initial power source for approximately a year prior to nuclear power system deployment (see Fig. 2). This became necessary due to budget constraints in the development cycle of the nuclear power system. The backup power system is sized to accommodate the charging of the autonomous surface vehicles, crawler-crane and utility rovers and must provide power during lunar night [approximately 14 earth days (336 hours) in duration]. To serve in this capacity it was determined that the system must provide approximately 100kWe and sustain emergency activities for up to 16 days when acting as backup (14 day lunar night plus two days of contingency). The requirement of sustaining Lunar Base operations during the lunar night prevented the sole use of solar arrays; some type of power storage would also be necessary. A trade study was conducted to examine the use of batteries, fuel cells (FCs), and regenerative fuel cells (RFCs) as alternatives or in combinations.

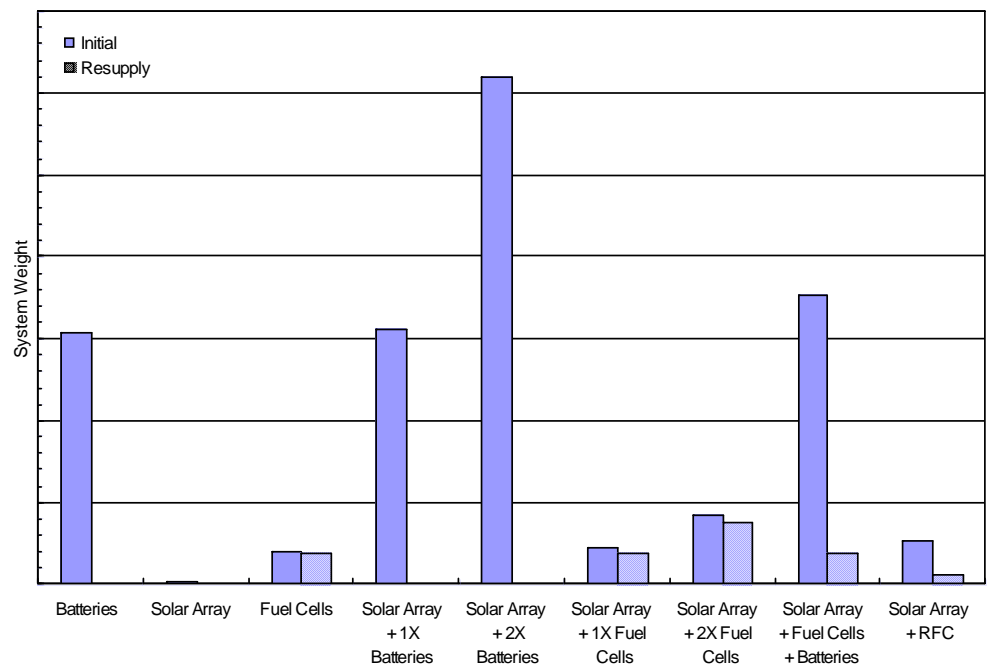

Figure 12. Comparison of Backup Power System Weights.

Results of the trade showed that an all battery system could be employed for reasonable weight, an all FC system was unrealistic due to the large propellant mass required to sustain a 14-day lunar night, and a combination solar cell and battery system did not show significant weight savings compared to an all battery system, but provides a backup system capable of supporting multiple lunar night cycles. Other combinations considered are shown in Fig. 12. In addition to the system weight, the resupply propellant mass to use the FCs (and RFCS) for an additional lunar night is also displayed in the figure.

Based on the system weight comparison, the backup power system baselined for this lunar architecture was the RFC-solar array combination. Initially there is an increase in the RFC-solar array combination system weight, but the weight savings over the nonregenerative fuel cells for multiple lunar night cycles and resupply mass of the reactants make the RFCs a more plausible option for a backup system. This system also has a weight that is within the capability of the Transportation System, specifically the HLLV and CLL. The selected power system should be able to provide the required power through the 13 lunar days and nights within the first year. The total mass of the RFC-solar array 
system is estimated to be approximately $5,443 \mathrm{lbm}$. The backup power system provides power to surface assets via a series of redundant cables and power nodes.

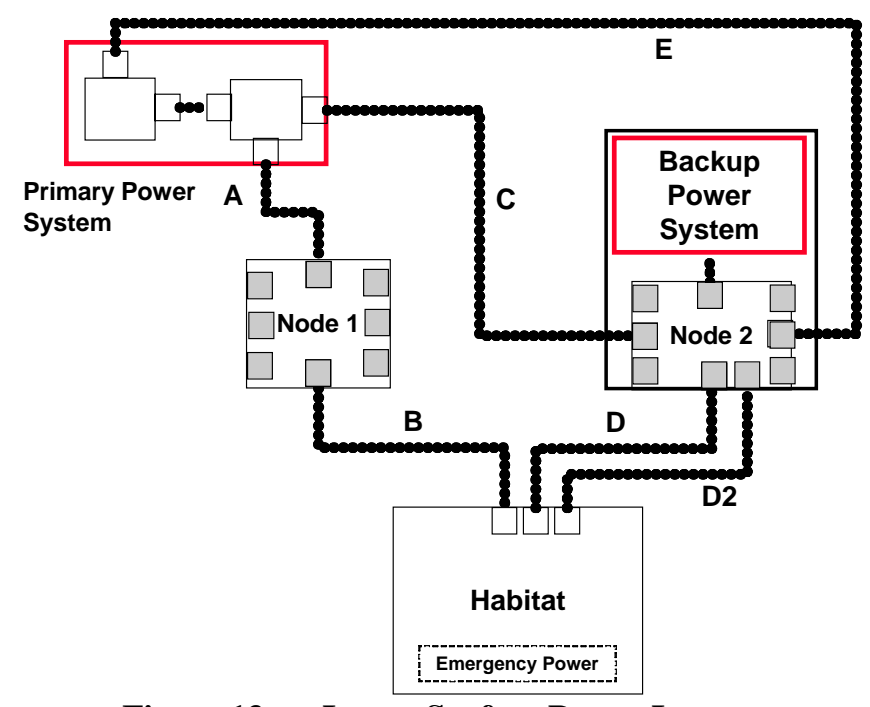

Figure 13. Lunar Surface Power Layout.

To ensure crew safety and meet Human Rating Requirements during sustained operations fault tolerance was considered in the layout and deployment of the primary and backup power systems. In addition to this, connectivity was evaluated to ensure power to vital systems during all conditions to enable repair operations or crew abort. The lunar surface power distribution system is depicted in Fig. 13. Critical to this layout were the use of two power distribution nodes and six cables and the assumption of two nuclear systems as part of the primary power system. In addition to power distribution, the nodes also provide access to surface mobility assets for recharging and the second nuclear power plant provides additional system redundancy. As an additional level of safety each habitat module is equipped with emergency power, providing sufficient power to allow time for the crew to don EVA suits and evacuate the habitat during an

emergency.

The standard NASA approach of designing human rated system with two-fault tolerance capability was applied to the lunar surface infrastructure. To assess the human rating compliance of this system, a failure matrix was created to assess the impact of single and dual failures of any combination of the major elements and indicate the resulting mission condition. Three possible mission conditions were examined: Fail Op (FO), Fail Safe Backup (FSB), and Fail Safe Emergency (FSE). Analysis showed that the proposed layout in Fig. 13 has 10 potential FSE scenarios out of 100 cases examined. A FSB condition is one where both the primary and backup power systems can no longer supply power to the habitat to sustain nominal or emergency operations and the crew must use the emergency power located in the habitat. Recall this is enough power for the crew to don EVA suits and evacuate the habitat. In conclusion, this power configuration meets Human Rating Requirements.

A final note on the power distribution system is that approximately $5 \mathrm{~km}$ of cables are required for power connectivity. Each cable is deployed and buried (thermal and micro-meteoroid protection) using the trencher utility rover. The six cables shown in Fig. 13, A through E. The cables comprise the required $5 \mathrm{~km}$ of cables.

\section{Lunar Life Support Systems}

One of the most critical Lunar Base subsystems for sustaining life during an exploration mission is the Environmental Control and Life Support System (ECLSS). The ECLS System manages the atmosphere, water, waste, and food. ${ }^{12}$ This system closely replicates the ECLSS that is found in human spaceflight systems today but with two exceptions. First, the most critical aspect to system sizing, the Lunar Base ECLSS is required to control a much larger volume, due to the habitat module's size, than one would find in a spacecraft. Second, Lunar Base ECLSS subsystems can leverage the moon's small gravitational force.

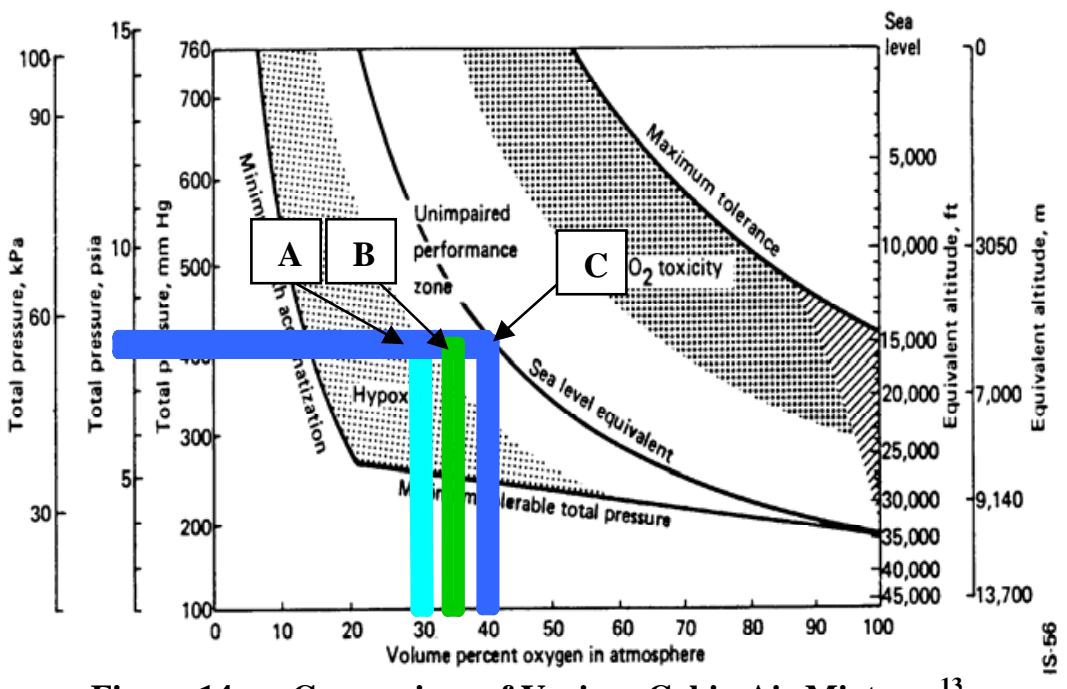

Figure 14. Comparison of Various Cabin Air Mixtures ${ }^{13}$ 
Two parameters of the ECLS System that were determined was the operating pressure and air mixture ratio. The desire is to have a low operating pressure to limit the time required to pre-breathe for Surface Excursion Activities (SEAs) and to limit the leakage rates on the habitat. The trade-off that occurs is the lower the total operating pressure, the greater concentration of oxygen is required to keep up the oxygen partial pressure. High concentrations of oxygen can lead to an unsafe crew environment due to high flammability, e.g. Apollo 1 fire, and could lead to oxygen toxicity if the pressure is not moderated. The baseline environment that was selected was a $55.2 \mathrm{kPa}$ (8 psi), $40 \% \mathrm{O}_{2}$ and $60 \% \mathrm{~N}_{2}$ mixture. In Fig. 14, it can be seen that this atmosphere composition occurs at Point C. This point coincides with the Sea Level Equivalent curve with the implication that crew physiology, i.e. breathing and circulation, would behave similarly as they would at Sea Level on Earth. Many Lunar Base architectures and pressurized rovers that were researched during the CE\&R study selected a pressure of $57.2 \mathrm{kPa}(8.3 \mathrm{psi})$ with a mixture of $30 \% \mathrm{O}_{2}$ and $70 \% \mathrm{~N}_{2}$. This data corresponds to Point $\mathrm{A}$ in Fig. 14. As can be seen in the figure, this borders the Hypoxia region, which is "the condition of insufficient oxygen to support physiological functioning." $"$ This condition could dangerously affect the crew by causing hallucinations, excitation, paralysis, loss of memory, and in the worst case, death. These are all detrimental effects to the crew and also the mission.

While this is an atmosphere that the crew can acclimate to, physical exertion could push a crewmember to oxygen deprivation. By being on the cusp of the hypoxia region, there is no safety factor to the crew in the event of an ECLSS malfunction. Applying a higher percentage of oxygen provides some reassurance to the issue of hypoxia, but creates a new safety concern of the flammability of the atmosphere. Table 4 highlights the flame-spread rates at Earth gravity and at quiescent gravity of different oxygen atmosphere compositions and different diluents. At the Lunar Base's baseline atmosphere composition of $40 \% \mathrm{O}_{2}, 60 \% \mathrm{~N}_{2}$, the flame-spread rate is $2.0 \mathrm{~cm} / \mathrm{s}$. For the lunar bases with a $30 / 70 \mathrm{O}_{2} / \mathrm{N}_{2}$ split, the flamespread rate is $1.1 \mathrm{~cm} / \mathrm{s}$. This is a decrease (more safe) of $45 \%$ in the flammability over our baseline design. The analysis resulted in selecting an air composition of $35 / 65 \mathrm{O}_{2} / \mathrm{N}_{2}$ (flame spread rate of 1.4 $\mathrm{cm} / \mathrm{s}$ ), a compromise between oxygen composition and flammability. This had a small increase in atmosphere flammability over the 30/70 mixtures (27\% increase), but also allows the crew margin to perform physiological functions.

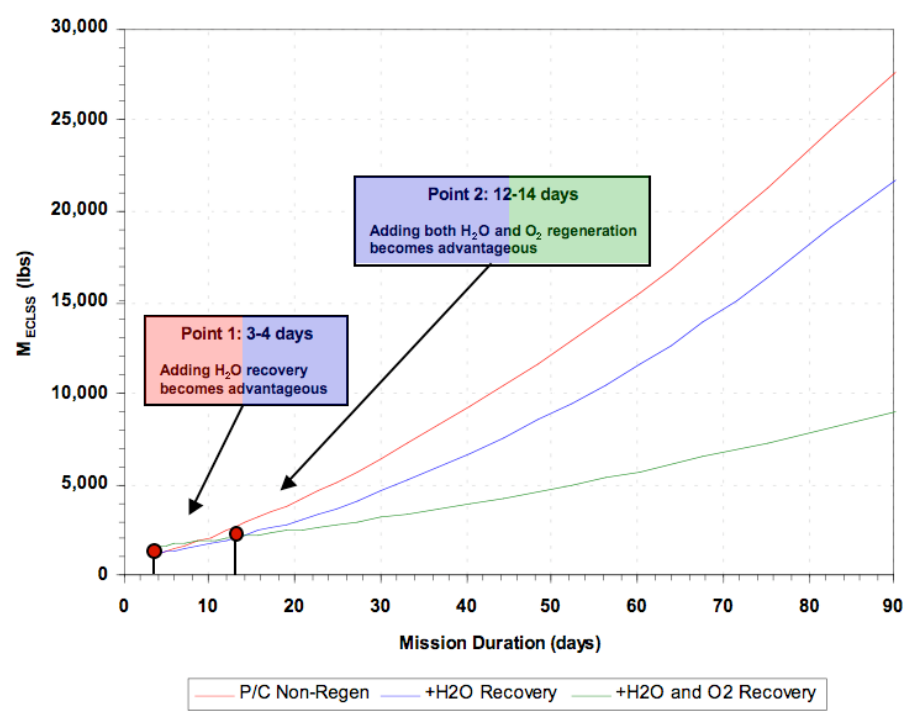

Figure 15. Break-even Points of ECLS Systems with Various Levels of Closure.
Table 4. Flammability of Thin

Cellulosic Sheet Fuels Under Atmospheres with Varying Diluents. ${ }^{14}$

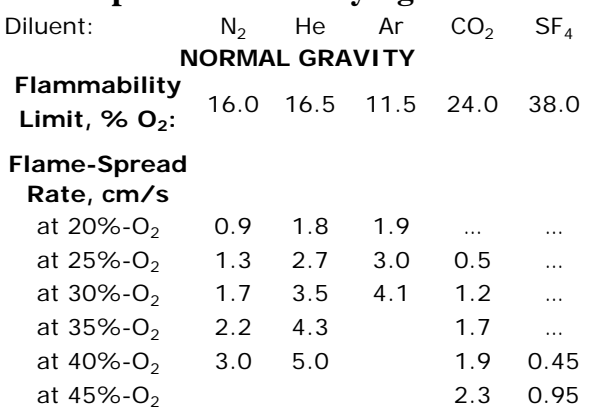

QUI ESCENT MI CROGRAVITY

Flammability

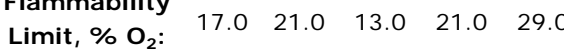

Flame-Spread

Rate, $\mathbf{c m} / \mathbf{s}$

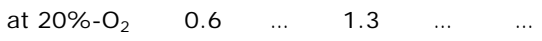

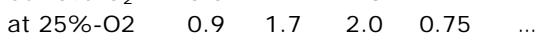

$\begin{array}{llllll}\text { at } 30 \%-02 & 1.1 & 2.1 & 2.6 & 1.3 & 0.35\end{array}$

$\begin{array}{llllll}\text { at } 35 \%-\mathrm{O} 2 & 1.4 & 2.4 & 1.7 & 0.6\end{array}$

$\begin{array}{lllll}\text { at } 40 \%-\mathrm{O} 2 & 2.0 & 2.5 & 1.9 & 1.0\end{array}$

The major trade that took place for Life Support Systems was open v. closed loop systems. The terms "open" and "closed" refer to amount of reusability in the system. An open loop system contains no reusable features and must be replenished after the consumables are used but has the benefit of being simple and highly reliable. A closed loop system is the other extreme where all resources are recycled, which saves transportation resources required for resupply. In between the two extremes are various levels of closure. For the CE\&R study, an analysis was performed to look at the Technology Readiness Levels (TRL) of technology required to close the loop. Of the four areas the ECLS System manages (atmosphere, water, waste, and food), it was seen that a combination of the greatest mass savings and mature technology were found in the atmosphere and water areas for regeneration. The strategy was to close these

12

American Institute of Aeronautics and Astronautics 
two areas as much as technically feasible with estimates of current TRLs. As in the power situation, budget was not available to develop all necessary technologies immediately for the start of the campaign. Although it was determined that closing the ECLSS loop as much as technically permissible was important to the success of long duration missions, developing the vehicles and habitats were considered the priority for initial budget dollars. A trade-off exists between reusability and mass and mission duration and can be seen in Fig. 15. This chart was prepared for the Lunar Lander, but can also be applied to the Lunar Base since the crew size is the same and therefore the amount of waste products are the same. The only change that would exist between the two scenarios is that the Lunar Base ECLSS mass would be increased due to more fans required to move the large volumes of air in the habitat modules. This would translate all the curves along the $+y$ axis equally but the mission duration between the different systems would be the same. Closed-loop systems have an increased system mass compared to Openloop systems due the subsystems required for recycling the resources. For short-duration missions, an open loop system is more mass efficient. Conversely, a closed-loop system is more efficient for long duration missions. An indepth sizing analysis needs to be performed to understand the break-even point of the two systems. The mass related to open-loop systems is thoroughly understood due to their usage in current and historical spacecraft. The unknown is the mass of the closed-loop system. More research and development is required of closed-loop systems to increase the level of fidelity of system mass and understanding of the break-even point.

Table 5 compares three different ECLS Systems, open loop, closed loop, and bioregenerative. This data shows closed loop ECLSS save approximately three missions/year (based on 4 crew missions). This is more beneficial that insitu oxygen production from lunar regolith. Adding this function to the ECLSS loop will save approximately two logistic missions/year.

Table 5. Logistics Mission Needed per Year ${ }^{17,18}$

\begin{tabular}{|c|c|c|c|c|c|c|c|c|c|c|c|c|}
\hline & \multicolumn{4}{|c|}{ Open Loop } & \multicolumn{4}{|c|}{ Closed Loop } & \multicolumn{4}{|c|}{ Bioregenerative } \\
\hline & 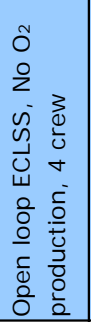 & 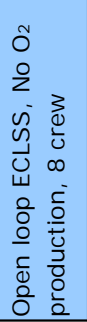 & 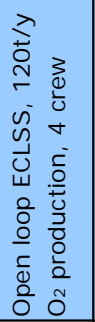 & 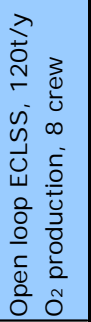 & 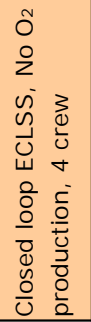 & 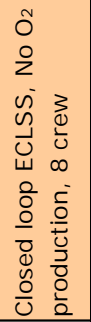 & 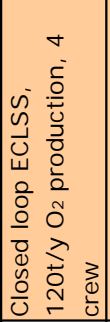 & 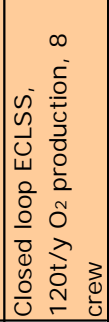 & 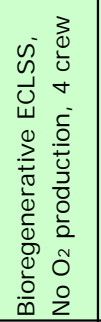 & 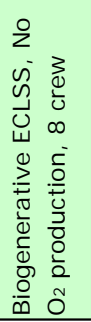 & 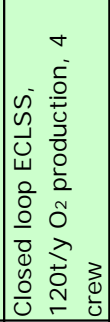 & 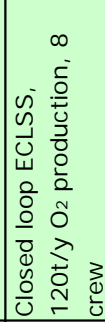 \\
\hline Resupply (2 launches) & 38.7 & 38.7 & 8.5 & 8.5 & 38.7 & 38.7 & 8.5 & 8.5 & 38.7 & 38.7 & 8.5 & 8.5 \\
\hline Spares & 6.8 & 6.8 & 8.1 & 8.1 & 6.8 & 6.8 & 8.1 & 8.1 & 37.1 & 37.1 & 18.1 & 18.1 \\
\hline Expendables & 1.4 & 1.4 & 1.6 & 1.6 & 1.4 & 1.4 & 1.6 & 1.6 & 7.4 & 7.4 & 3.6 & 3.6 \\
\hline Consumables & 44.4 & 88.7 & 44.4 & 88.7 & 3.8 & 7.5 & 3.8 & 7.5 & 2.9 & 5.8 & 2.9 & 5.8 \\
\hline Total (metric tons) & 91.3 & 135.6 & 62.6 & 106.9 & 50.7 & 54.4 & 22.0 & 25.7 & 86.1 & 89.0 & 33.1 & 36.0 \\
\hline Total \# of Launches & 6.5 & 9.7 & 4.5 & 7.6 & 3.6 & 3.9 & 1.6 & 1.8 & 6.2 & 6.4 & 2.4 & 2.6 \\
\hline
\end{tabular}

The architecture described in this paper uses a partially closed-loop system. As can be seen in the manifest shown in Fig. 2, the first human mission will be a 14-earth day mission. This duration falls within the zone where an open-loop system is more mass optimized compared to the closed-loop system. By using an open-loop system for the initial mission, closed-loop ECLSS development dollars were pushed into the following year in order to meet the annual budget allocations. The open-loop system will require consumables for the crew. The selected solution was a containerized system, once again using the commonality of the CC. The CC's would contain enough $\mathrm{O}_{2}, \mathrm{~N}_{2}$, and water to support 60 crew-days. For the assumed crew of four, this would support the crew for 15 days. This means that the first 14-day mission could be performed solely through the use of one of these CCs. The CCs would be transported adjacent to the habitat modules via robotic units and interface with the habitat through smart umbilicals. Smart umbilicals is a technology that has launch vehicle heritage and was being developed under the Space Launch Initiative. They permit automated mating, demating, and remating. As the closed-loop technology matures and is included into the system, the longer duration missions become feasible. A conservative efficiency assumption of $80 \%$ was applied for the closed-loop system. An efficiency rate in the $90^{\text {th }}$ percentile should be achieved with new technologies. Since the efficiency is not maxed out at $100 \%$, this is a partial closed-loop system; consumables would still be required to "top-off" the system. Since the closed-loop system would be a developing technology and it is uncertain when the technology would actually be deployed, the ECLS System was decoupled from the habitat modules and is envisioned to be a modular system contained in the volume of a CC. 


\section{Lunar Surface Mobility Systems}

Lunar Surface Mobility Systems (LSMS) is a broad category that covers the robotic rovers and the human rovers. Robotic rovers include the Backhoe Utility Rover, Trencher Utility Rover, and Crawler Crane. The Unpressurized and Pressurized rovers fall under the Human Controlled Rover classification.

\section{Robotic Rovers}

The robotic rovers are essential for preparing the Lunar Base infrastructure prior to the first manned mission. The launch manifest proposes the first rovers to land on the lunar surface in late 2017 with the compliment of robotic rovers to land in 2018. This allows the robotic rovers time to assemble, construct, and perform the necessary tasks to prepare for human exploration and extended stays. The process for conceptualizing the rovers started with a list of requirements, which fed into a list of functions. The derived functions of the rovers would be to carry, to dig, and to bury. The "carrying" function was optimized by creating one vehicle that transports large items (e.g. habitat modules, clusters of cargo containers) and one that carries smaller loads, such as individual CCs and regolith. Where possible, multiple functions were coupled in a single vehicle to conserve volume/mass on cargo lander flights, but also to save on vehicle development since each new vehicle would be required to go through the Design, Development, Test, and Evaluation (DDT\&E) cycle. Another consideration for the trade space was a minimum number of rovers. A minimum number optimizes the launch manifest and DDT\&E; however, it also

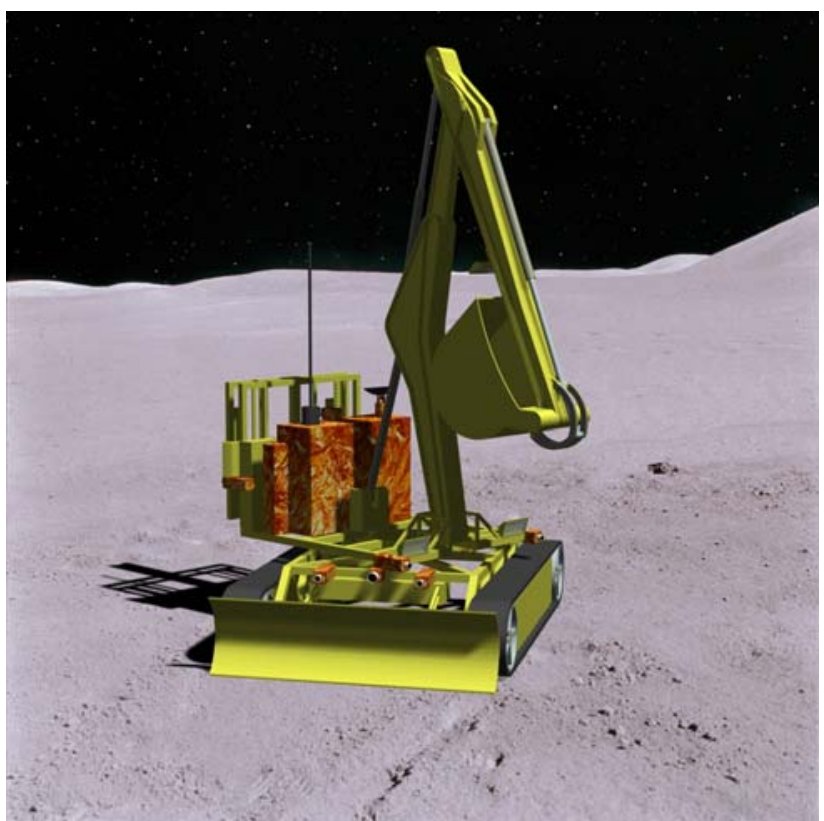

Figure 16. Backhoe Utility Rover in Stowed Configuration.

constrains the number of tasks being performed at any given instance in time. The trade-off of optimizing the manifest and vehicle DDT\&E is the operations, the fewer robotic rovers, the more restricted the operations because tasks will have to be performed serially as opposed to in parallel. The list of required rovers was narrowed to three robotic rovers, the Backhoe Utility Rover, Trencher Utility Rover, and Crawler Crane. These robotic rovers provide low-speed, regolith moving, grading, lifting, trenching, and cable laying capabilities.

The Backhoe Utility Rover (see Fig. 16) was conceptually designed to handle the grading, lifting of smaller objects, and placement. It consists of a base unit that includes the frame, motors, treads, and dozer blade and an upper portion that is comprised of a rotating base with a backhoe, electric subsystems, and fork lift. Backhoe articulation is accomplished by electromechanical actuators. The forks on the forklift are conceptualized to rotate into a vertical position to consume less area on the Cargo Lunar Lander. One of the duties of the Backhoe Utility Rover is the placement of regolith. This is required for the Crawler Crane to use the regolith as a counter balance (more mass effective to send the Crawler Crane without necessary counter balance) but also for assisting with the regolith used on the habitat modules and airlocks for radiation shielding. The backhoe has the capability to release regolith up to a

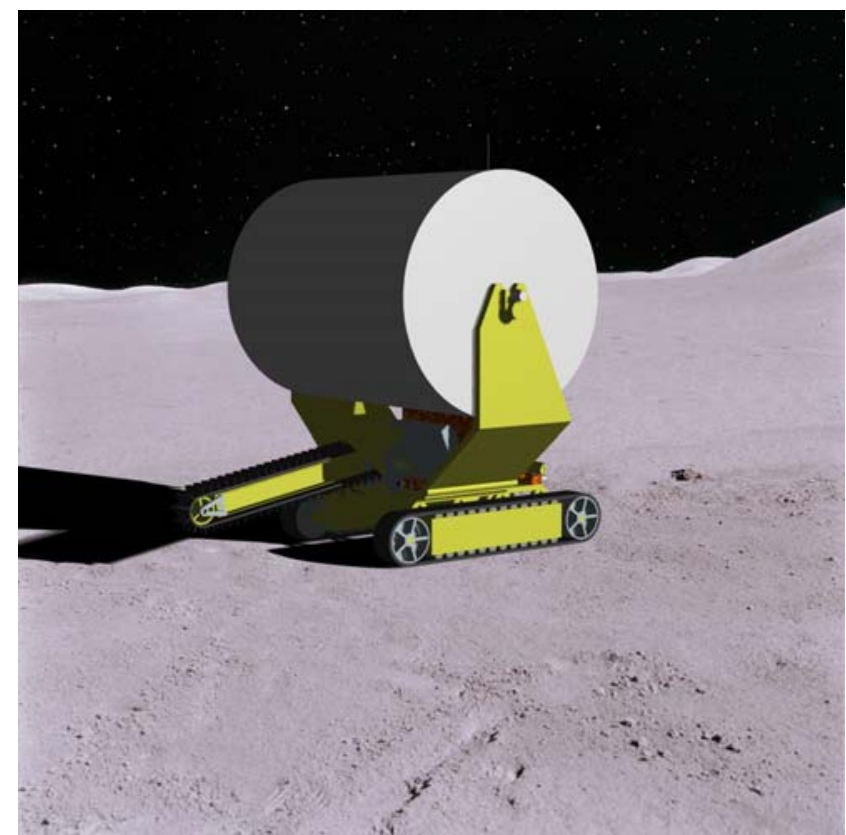

Figure 17. Trencher Utility Rover with Cable Spool. 
maximum height of 17 feet. Another tool included in the Backhoe Utility Rover is the forklift. The forklift was included for the transport and placement of the smaller Lunar Base elements such as the CCs and airlocks. The forklift also gives redundant capability of removing the CCs and airlocks from the CLL (nominally the responsibility of the Crawler Crane). Due to the mass of the airlocks and CCs, it is necessary for the backhoe to be extended to counter balance the load. This avoids the inclusion of non-functional mass (i.e. ballast) and aids in optimizing the mass of the cargo manifest for the CLL. The conceptual design of the Backhoe Utility Rover also includes a dozer blade. The blade performs the function of grading areas in preparation of habitat modules, CCs, and airlocks. The dozer blade is also used to fill trenches where power cables are laid. To perform this function, the dozer blade will be angled to direct the regolith into the trench to cover and protect the power cables from radiation and micro-meteorite damage.

The creation of the utility trench is the responsibility of Trencher Utility Rover (seen in Fig. 17). Similar to the Backhoe Utility Rover, the Trencher Utility Rover was conceptually designed to include multi-function capability. Outside of vehicle locomotion, the Trencher Utility Rover has the capability to break up bedrock with dual jackhammers, create a two-foot deep trench, and lay cable within the trench. In contrast to the Backhoe Utility Rover, the Trencher Utility Rover will not have a rotating platform. This was done intentionally since the rover's required actions would always be in a straight line parallel to the rover's tracks. The task of laying cable would be done in two passes. The first pass would be required to break-up rocks and create the trench. The rover would then raise the jackhammers and rotate the trencher out of the way and then reverse its course to lay the cable on the second pass.

The last of the robotic rovers implemented in this lunar base architecture is the Crawler Crane. This rover is essential for lifting the massive items such as the habitat module and cargo pallets (used to transport 7 CCs simultaneously). Due to the mass of the Crawler Crane and that it is required before most

Table 6. Crawler v. Crane Trade Study Summary

\begin{tabular}{|c|c|c|c|c|}
\hline & $\begin{array}{c}\text { Crawler } \\
\text { Advantages }\end{array}$ & $\begin{array}{c}\text { Crawler } \\
\text { Disadvantages }\end{array}$ & $\begin{array}{c}\text { Crane } \\
\text { Advantages }\end{array}$ & $\begin{array}{c}\text { Crane } \\
\text { Disadvantages }\end{array}$ \\
\hline $\begin{array}{l}\text { Mass } \\
\text { Estimate }\end{array}$ & & & Lighter & \\
\hline CLL Storage & & Spread out & $\begin{array}{l}\text { Packages tightly } \\
\text { in CLL center }\end{array}$ & \\
\hline Outfitting & $\begin{array}{l}\text { Ready to work } \\
\text { after } \\
\text { deployment }\end{array}$ & & & $\begin{array}{l}\text { Needs ballast } \\
\text { installed }\end{array}$ \\
\hline $\begin{array}{l}\text { Travel and } \\
\text { Terrain } \\
\text { Negotiation }\end{array}$ & $\begin{array}{l}\text { Automatically } \\
\text { aligns with off- } \\
\text { level lift. Made } \\
\text { to carry and lift }\end{array}$ & $\begin{array}{l}\text { Track alignment } \\
\text { whlie moving }\end{array}$ & $\begin{array}{l}\text { Tracks tied } \\
\text { together on } \\
\text { base }\end{array}$ & $\begin{array}{l}\text { Load stability } \\
\text { while moving }\end{array}$ \\
\hline $\begin{array}{l}\text { Reach and } \\
\text { Precision }\end{array}$ & & $\begin{array}{l}\text { Must surround } \\
\text { object to } \\
\text { interface. Lifting } \\
\text { tied together by } \\
\text { "C" shape. }\end{array}$ & & $\begin{array}{l}\text { Reach to } \\
\text { interface object. } \\
\text { Independent } \\
\text { lifting at } \\
\text { multiple } \\
\text { locations }\end{array}$ \\
\hline DDT\&E & & $\begin{array}{l}\text { Complete new } \\
\text { vehicle }\end{array}$ & \begin{tabular}{|l} 
Terrestrial \\
version exists
\end{tabular} & \\
\hline
\end{tabular}
infrastructure arrives on the lunar surface, it has the requirement to self-deploy. Two concepts were conceived to perform the heavy lift function. One concept was to interface with the sides of the habitat modules and lift using a motorized pulley system (see Fig. 18a). This required interface locations on the side of the habitat. The second concept was a self-erecting crane (see Fig. 18b), which required interface locations on the top of the habitat modules. The summary of the trade study can be seen in Table 6 . While both concepts had their advantages and disadvantages, the decision was made to pursue the Crane concept given the advantage of having existing heritage

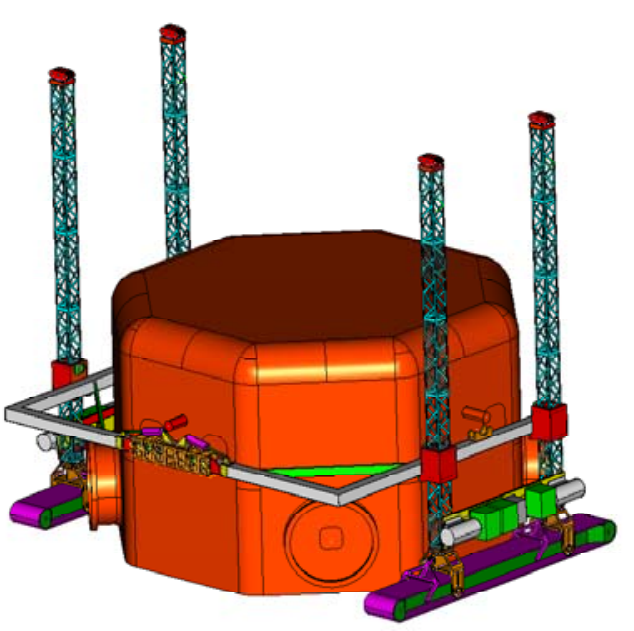

a)

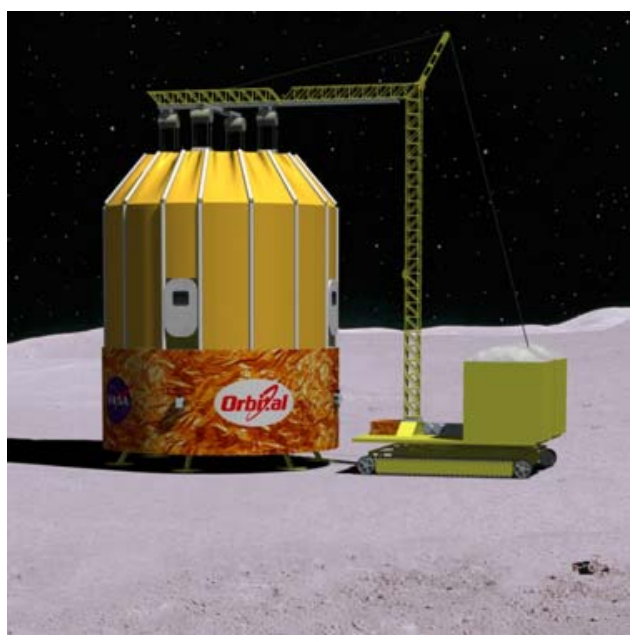

b)

Figure 18. Crawler Concepts. a) Crawler Lift with Preliminary Habitat Module Concept b) Crawler Crane with Recommended Habitat Module. 
on Earth (through crane manufacturing companies such as Manitowoc and Liebherr) and mass properties. Due to the cantilevered structure of the crane and the moment created when lifting, a counter balance is required. To minimize the mass of the crane, the counterbalance was omitted for the launch and in-space transport segment. A container structure was included in the crane concept to capitalize on lunar in-situ resources by using the regolith as the counterbalance. The Backhoe Utility Rover would be implemented to fill the regolith containers on the Crane.

\section{Human Controlled Rover}

Rovers to transport humans will be required for the exploration missions. Initially, an Unpressurized Crewed Rover (UCR) would be necessary for the crew to expand the circle of knowledge. The UCR provides crew transportation limited by the oxygen supply of the crew. Safety limitations will restrict the distance away from the lunar base. The distance requirement used for this study was the amount of air consumed by the crew walking back to the Lunar Base assuming the UCR breaks down. The concept implemented in this study for the UCR closely resembled the Apollo LRV and carries four crewmembers. A conceptual design of the UCR can be seen in Fig. 19a. Outside of seating four crewmembers, the cosmetic difference between the Apollo LRV and the UCR is the roll bar. This is included for crew safety. Other items included for crew safety include floodlights and navigation sensors. To limit the amount of lunar dust kicked up by the tires, fenders were added.

Eventually, attention will be directed to exploration missions further from the Lunar Base. Due to the distance of these missions and the duration associated with them, the UCR would not be able to support the crew. A safe haven would also be required to protect the crew from SPEs and provide consumables to sustain the crew in the event of a malfunction and a rescue mission is needed. For these reasons, a Pressurized Crew Rover (PCR) has been added to the architecture, but is not implemented until 2023 to delay development cost. From an operations standpoint much research and exploration can be done with the UCR and also with robotic units. Many studies on pressurized rovers already exist. It was the strategy of this study to capitalize on previous studies and spend resources performing on trade studies and conceptually designing the other elements. To this extent, the design proposed by Roger Arno, the Lunar Polar Mission Rover, was selected. ${ }^{15,} 16$ The conceptual design of a slightly modified Lunar Polar Mission Rover is shown in Fig. 19b.

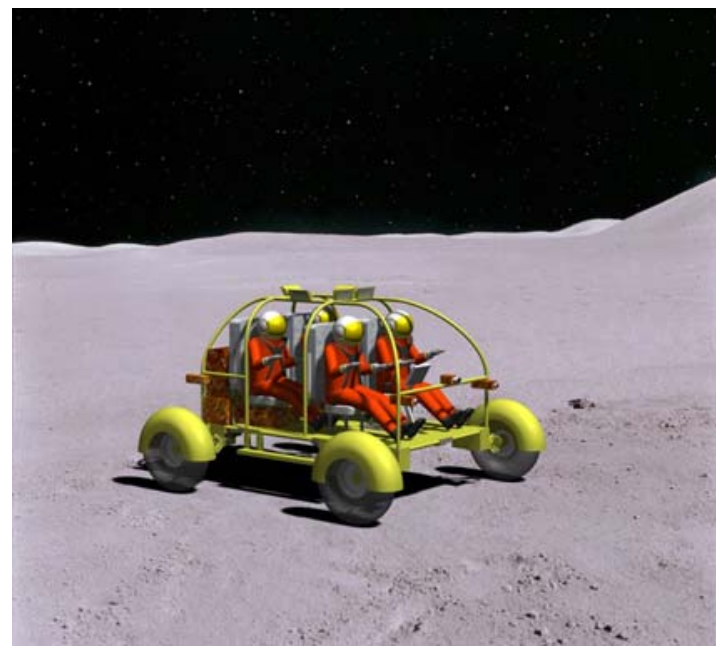

a)

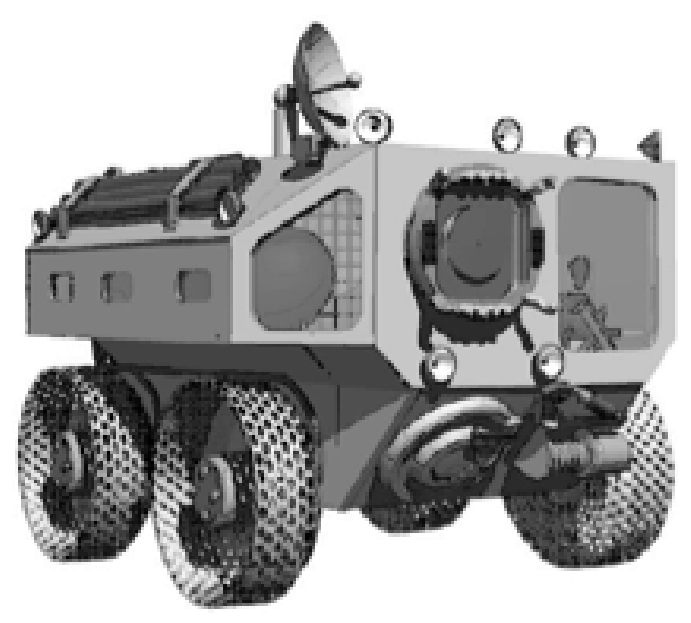

b)

Figure 19. Human Controlled Rovers. a) Unpressurized Crew Rover b) Lunar Polar Mission Rover ${ }^{15}$ (Pressurized Crew Rover).

\section{Conclusion}

The Lunar Base portion of the CE\&R study was an architecture level solution. It is critical to examine the Exploration architecture as an entire system. While it is desirable to have large habitats, they are restricted by the weakest link in the architecture, whether that is the capability of the launch vehicle, performance of the lunar lander, or by the deployment mechanism off the lunar lander. More work is required to refine the details of the conceptual designs proposed in this paper. However, the work performed did show that advances in closed-loop ECLS systems, nuclear power, regenerative fuel cells, radiation shielding, and lunar dust mitigation technologies are required to 
sustain a human presence on the moon. Analysis showed that closure of the ECLSS loop is the single most effective means of achieving long duration missions. Closed-loop ECLSS was seen to be even more critical than in-situ resources for generation of oxygen/water to optimize life support systems on extended duration missions.

Also very visible in this architecture was the relationship of low cost development and operations and the minimum number of elements. The key component of this is maximizing the amount of reusability and modularity in the system. The major elements in this architecture have been maximized for commonality, but it is acknowledged that there is a level of expendability that exists. More work would be required to design reusability into elements such as the Cargo Container (CC) in both its cargo and ECLSS variants. However it was also noted that there are diminishing returns with respect to reusability when development money and schedule are considered. Modularity was seen as very beneficial in the architecture as it allowed infusion of newer technologies without requiring sweeping infrastructure upgrades. This was especially evident in transforming to the partial closed-loop ECLS System and in the power generation.

\section{Acknowledgments}

The work presented in this paper could not have been possible without the support and contributions from the entire CE\&R team. This includes our subcontractors during the study, ATA Engineering, Spaceworks Engineering Inc., and Futron, who contributed with many analyses and provided data to support the derived architecture.

\section{References}

${ }^{1}$ Bocam, K.J., et al., “A Space Exploration Architecture for Human Lunar Missions and Beyond,” AIAA, $1^{\text {st }}$ Space Exploration Conference: Continuing the Voyage of Discovery, AIAA 2005-2529, Orlando, FL, 2005.

${ }^{2}$ Leo, R., and Bocam, K.J., “Development of a Lunar Lander,” AIAA Space 2006 (to be published).

${ }^{3}$ Simonsen, L.C., "Analysis of Lunar and Mars Habitation Modules for the Space Exploration Initiative (SEI)," Shielding Strategies for Human Space Exploration, NASA Conference Publication 3360, NASA, Houston, TX, 1995, pp.49-58.

${ }^{4}$ Carrier, W.D., Olhoeft, G., and Mendell, W., “Physical Properties of the Lunar Surface,” Lunar Sourcebook: A User's Guide to the Moon, edited by G.H. Heiken, D.T. Vaniman, and B.M. French, Cambridge University Press, New York, 1991 , Chap. 9.

${ }^{5}$ James, J. T., Ph.D., “Mammalian Toxicity of Lunar Dust and Related Simulants,” NASA, Biological Effects of Lunar Dust Workshop, 2005.

${ }^{6}$ Papike, J., Taylor, L., and Simon, S., “Lunar Minerals,” Lunar Sourcebook: A User's Guide to the Moon, edited by G.H. Heiken, D.T. Vaniman, and B.M. French, Cambridge University Press, New York, 1991, Chap. 5.

7"Lunar Electric Power Systems Utilizing the SP-100 Reactor Coupled to Dynamic Conversion Systems (Task Order NO. 12),” Rockwell International, Rocketdyne Division, Canoga Park, CA, NASA CR-191023, Mar. 1993.

${ }^{8}$ Mason, L. E., Bloomfield, H. S., and Hainley, D. C., "SP-100 Power System Conceptual Design for Lunar Base Applications,” NASA TM-102090, 1989.

${ }^{9}$ Mason, L. S., Rodriguez, C. D., Hanlon, J. C., and Mansfield, B. C., "SP-100 Reactor with Brayton Conversion for Lunar Surface Applications,” NASA TM-105637, Jan. 1992.

${ }^{10}$ Sovie, R. J., and Bozek, J. M., “Nuclear Power Systems for Lunar and Mars Exploration,” NASA TM-103168, Oct. 1990.

${ }^{11}$ McGuire, M. L., Martini, M. C., Packard, T. W., Weglian, J. E., and Gillard, J. H., "Use of High-Power Brayton Nuclear Electric Propulsion (NEP) for a 2033 Mars Round-Trip Mission,” NASA TM-2006-214106, March 2006.

${ }^{12}$ Doll, S., and Eckart, P., “Environmental Control and Life Support Systems (ECLSS),” Human Spaceflight: Mission Analysis and Design, edited by W.J. Larson and L.K. Pranke, McGraw Hill, New York, pp. 539-573.

${ }^{13}$ Friedman, R., "Fire Safety in the Low Gravity Spacecraft Environment," Society of Automotive Engineers, 1999-01-1937, 1999.

14»Natural and Induced Environments," Man Systems Integration Standards: NASA STD-3000, Vol. 1, Rev B, NASA, Houston, TX, 1995, Chap. 5.

${ }^{15}$ Arno, Rodger, “ Planetary Surface Vehicles,” Human Spaceflight: Mission Analysis and Design, edited by W.J. Larson and L.K. Pranke, McGraw Hill, New York, pp. 447-476.

${ }^{16}$ Zakrajsek, J. J., et al., "Exploration Rover Concepts and Development Challenges," AIAA, $1^{\text {st }}$ Space Exploration Conference: Continuing the Voyage of Discovery, AIAA 2005-2525, Orlando, FL, 2005. 